\title{
Structural Characteristics and Reactivity Relationships of Nitroaromatic and Nitramine Explosives - A Review of Our Computational Chemistry and Spectroscopic Research
}

\author{
Mohammad M. Qasim ${ }^{1}{ }^{*}$, Brett Moore ${ }^{1}$, Lyssa Taylor ${ }^{1}$, Patricia Honea ${ }^{3}$ Leonid Gorb ${ }^{1,2}$, and \\ Jerzy Leszczynski ${ }^{1,4}$ \\ 1 USAE ERDC EL, 3909 Halls Ferry Road, Vicksburg, MS, USA \\ 2 SpecPro Contractor \\ 3 University of Mississippi Medical Center, Jackson, MS \\ 4 Computational Center for Molecular Structure and Interactions, Jackson State University, Jackson, \\ MS, USA \\ * Author to whom correspondence should be addressed; Email: qasimm@wes.army.mil; \\ Tel: +1-601-634-3422
}

Received: 14 November 2007; in revised form: 27 November 2007 / Accepted: 30 November 2007 /

Published: 13 December 2007

\begin{abstract}
Although much has been discovered, discussed and written as to problems of contamination by various military unique compounds, particularly by the nitrogen based energetics (NOCs), remaining problems dictate further evaluation of actual and potential risk to the environment by these energetics and their derivatives and metabolites through determination of their environmental impact - transport, fate and toxicity. This work comprises an effort to understand structural relationships and degradation mechanisms of current and emerging explosives, including nitroaromatic; cyclic and cage cyclic nitramine; and a nitrocubane. This review of our computational chemistry and spectroscopic research describes and compares competitive degradation mechanisms by free radical oxidative, reductive and alkali hydrolysis, relating them, when possible, to environmental risk.
\end{abstract}

Keywords: nitroaromatic / nitramine explosives; structural / activity relationships; degradation mechanisms 


\section{Introduction}

It is well known that actual and potential environmental risk assessment of nitrogen based energetic compounds (NOCs) is greatly complicated by the potential of these reactive compounds to form large numbers of environmental transformation products that can exhibit a wide range of physical properties and reactivities. In addition, physical properties such as aqueous dissolution rate, water solubility, partitioning to lipids and organic matter are important determinants of such environmental behavior as transport and bioaccumulation [1-11]. All these mentioned factors contribute to environmental risk, including hazard to personnel, in ways that are still mainly not assessed [8-9, 12-17]. So far, remediation methods for treating nitroaromatic and nitramine contaminants have included alkaline hydrolysis, advanced chemical oxidation processes utilizing hydroxyl radical initiators such as peroxone, dark and photo-enhanced Fenton's reagents, titanium dioxide and other semiconductors as well as photo-induced irradiation. Resultant problems have frequently included incomplete degradation and high cost as well as toxic and recalcitrant transformation products [18-53]. Also, resources have historically been made available for practical laboratory studies of only a very low percentage of NOCs and other compounds of military interest that become environmental contaminants [41-42]. In recent years, computational chemistry (CC) has enabled prediction and theoretical analysis of these and other NOCs not accessible for a variety of reasons, including those deemed too hazardous for experimental research. As computational and experimental data is compiled, the continuous accumulation of information can be expected to provide environmental scientists with means to expedite assessment of environmental risk as well as to prioritize emerging compounds for research and management [54-61].

This discussion of competitive degradation mechanisms of NOCs by free radical oxidative, reductive and alkaline hydrolysis deals with i) nitroaromatics: 2,4,6-trinitrotoluene (TNT); 1,3,5trinitrobenzene (TNB); 2,4,6-trinitrophenol (TNP or picric acid); ii) cyclic nitramines: hexahydro1,3,5-trinitro-1,3,5-triazine (RDX); octahydro-1,3,5,7-tetranitro-1,3,5,7-tetrazocine (HMX); iii) cage cyclic nitramines: 2,4,6,8,10,12-hexanitrohexa-azoisowurtzitane (CL-20); and 2,4,6,8tetranitro1,3,5,7-tetraaza-cubane (TNTAC), predicted but not yet synthesized; and iv) cage cubane: octonitrocubane (ONC). These compounds are shown in Figure 1.

Our hypothesis was proven computationally and spectroscopically: molecular structure, under homologous conditions, determines preferred, theoretically predictable degradation pathways. Thus, environmental impact - fate and effects - of energetic materials can also be predicted from their molecular structure. This hypothesis was examined through predictive methods, using quantum mechanical and classical force field mechanics to investigate most likely transition states and intermediates through comparison as to bond lengths and angles; heat of formation; steric energy; dipole moments; solvent accessibility and electrostatic potential surfaces; partial charges; and HOMO/LUMO energies. Then, since molecular structures exhibit characteristic spectra, ultraviolet (UV), visible (Vis) and Fourier Transform Infrared (FTIR) and Stopped Flow (SF) were used to test theoretical predictions and hypothesis by accomplishing the tasks of measuring concentration changes, following courses of reactions, and measuring changes in functional groups during appearances and disappearances of intermediate species. Since changes in UV/Vis/FTIR spectra were consistent with predictions, they constitute experimental verification [54-59]. Thus, combining CC prediction with 
experimental verification through spectroscopic techniques offers a flexible, clean, comparatively inexpensive and quick methodology that tracks subtle spectral changes while following rates of fastforming transition states, intermediate and final products. Where spectroscopic verification is used, it is described in the sections discussing the various compounds.

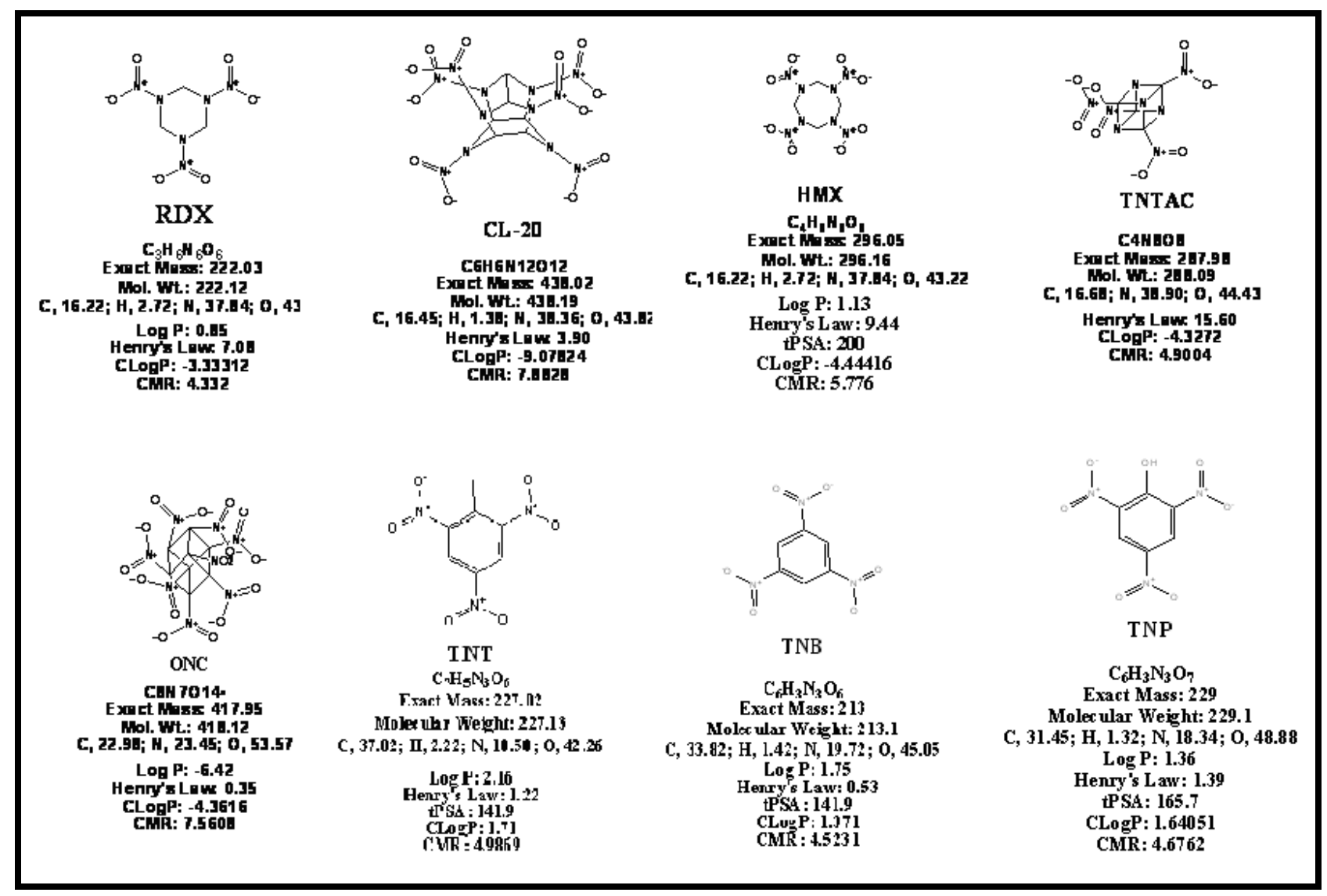

Figure 1. Selected cyclic and cage cyclic nitramine compounds and octonitrocubane (ONC).

\section{Utilization of Computational Chemistry Prediction}

\section{$2.1 \quad$ Theoretical}

Computational prediction reveals relationships between structures; stabilities; site, manner and degree of reactivity; and formation rates of both transition states and fast-forming intermediates leading to final products, thus disclosing transformation pathways. Computational analysis thereby enables further theoretical prediction as to most likely environmental products and interactions, important to facilitating assessment and management of NOC risks to the environment. Also, since predictive theoretical chemistry is based on the premise that molecular characteristics determine chemical and physical properties and reactivities, molecular structure can be correlated with a homologous series of molecules which, in turn, can be used to predict properties and reactivities of new members-providing a rational basis for predicting most probable environmental reaction mechanisms and transformation products. Given that a slight change in molecular structure can result in considerable change in chemical and, thus, environmental behavior of a compound, CC's powerful tools are needed to investigate these relationships. Improved computational methods are constantly 
being developed to accommodate various sizes of molecules as well as to give more precise calculations. Further, because of their accuracy, new methods can be expected to correlate particularly well with spectroscopic verification techniques.

\subsection{Application}

Quantum and classical (also known as "force field") mechanics from simple to complex were employed to characterize molecular properties of NOCs, revealing such physicochemical characteristics as functional groups; sites of reactivity; number of carbon-carbon (C-C), nitrogennitrogen $(\mathrm{N}-\mathrm{N})$ and carbon-nitrogen $(\mathrm{C}-\mathrm{N})$ bonds as well as number of nitro groups; size of molecules; symmetry; polarity; solvent accessible surfaces, and topography, all of which play their roles in determining structurally reactive behavioral relationships - such as toxicity and impact on the environment [54-60].

Semiempirical, e.g., quantum mechanical, computational tools were used to calculate bond lengths and angles; molecular orbitals; dihedral angles; formation and steric energies; partial charges, electrostatic potentials, and dipole charges/dipole moments; cosmo solvation; solvent accessibility; highest occupied molecular orbital (HOMO) and lowest unoccupied molecular orbital (LUMO). HOMO and LUMO not only indicate aspects of molecular structure but, as in the case of a CL-20 first tier derivative (discussed later), can reveal that the product is potentially toxic and recalcitrant. These semiempirical Molecular Orbital PACkage (MOPAC) methods, used first, quickly gave information sufficiently accurate to compare similar structural modes of transformation, with Molecular Mechanics (MM2 and MM3) employing classical mechanics to calculate such molecular parameters as steric hindrance - used for geometrical optimization and for distinguishing between stabilities of molecular conformers, both important parameters for the nitramine energetics. Modified Neglect of Differential Overlap (MNDO) and Austin Model (AM1) use Self-Consistent Field (SCF) approximations equally applicable to nitroaromatic and nitramine NOCs. Due to comparative values, AM1 is more suitable than MNDO for calculating minimized formation of crowded compounds such as nitroaromatics, whereas, AM1 better accounts for hydrogen bonding than MNDO. MNDO approximations are better suited than those of AM1 for non-planar cyclic non-aromatics, such as RDX, and for less crowded molecules [62].

Density Functional Theory (DFT) was utilized at various levels (mainly B3LYP) to calculate energies and other properties of both nitroaromatic and nitramine NOCs a priori as well as for verification and refinement of semiempirical predictive methods [63-65].

Quantitative Structural Property Relationships (QSPR) and Quantitative Structural Activity Relationships (QSAR) approaches were successfully applied to chemical/physical structural relationships. HOMO and LUMO values for nitroaromatic, nitramine and cage nitramine energetics were calculated. Definite trends were observed, e.g., the importance of position in substitution of amine or hydroxyl groups in nitroaromatic compounds. Different but definite trends were also seen for derivatives of nitramine and cage nitramine compounds. For instance, first tier derivatives, such as nitroso, hydroxyl amines and formation of double bonds on the ring were observed [66]. 


\section{Nitroaromatics}

\subsection{TNT (2,4,6-trinitrotoluene)}

\subsubsection{Background}

More than a century of production and extensive use of TNT have made it a major global soil and groundwater contaminant [8-11, 13, 24-25, 51, 67-69] with contaminated soil concentrations being reported to range from $10 \mathrm{mg} / \mathrm{kg}(\sim 47 \mu \mathrm{mol} / \mathrm{kg})$ to $12000 \mathrm{mg} / \mathrm{kg}(\sim 56000 \mu \mathrm{mol} / \mathrm{kg})$ [69] and sometimes as high as $35000 \mathrm{mg} / \mathrm{kg}$. Aqueous waste streams containing TNT concentrations as high as $70 \mathrm{mg} / \mathrm{L}(330 \mu \mathrm{M})$ have been reported [29]. At these concentrations, TNT is toxic, mutagenic, and potentially carcinogenic. Ingested TNT in small amounts manifests in headache, anemia, and skin irritation. Larger amounts of TNT can result in liver, eye and neurological damage [16]. Further, products of TNT metabolism in the human body interact with such macromolecules as DNA, causing genetic defects and cancer [14]. The chance of human contact is heightened by the fact of environmental bioaccumulation [4, 8-9].

Endeavors to effectively, rapidly and economically degrade TNT into less toxic intermediates with the goal of achieving complete transformation of TNT in contaminated soils and aqueous solutions have included both physico-chemical and biological means as well as efforts to incorporate chemical with biological means. Depending upon mode of degradation, difficulties have included high cost, incomplete/slow transformations, toxic resultant products, and lack of stability of treatment cultures [17, 21-22, 24-26, 29-30, 33, 36-37, 39, 41-43, 49-51, 67-71, 76-77].

\subsubsection{Structure}

The TNT carbon ring is planar and aromatic, with equal angles of $120^{\circ}$ [78]. The $\pi$ system of TNT is electron-deficient due to its planar aromatic structure where its $\pi$ electrons are drawn away from the ring by resonance towards the electron-withdrawing nitro groups. TNT electron deficiency and planarity make complexation possible with the non-bonding (n) electrons of a donating group, such as the oxygen atoms in a co-planar medium (e.g., in clay [10]), lessening TNT dissolution and mobility in the environment. Substitution at the ortho positions of TNT by such electron-donating groups as methyl, amino and hydroxide ions $\left(\mathrm{OH}^{-}\right)$can lessen the electron deficiency of the $\pi$ system and prevent co-planarity with electron donating groups from the media - thus minimizing complexation, which increases dissolution [79-85] and may, therefore, affect risk to the environment.

\subsubsection{Results of applied methods}

Sets of experiments designed to enhance biodegradation [41-43, 50, 86] were carried out with further expectation that loss of aromaticity would lead to degradation. TNT was chemically transformed into products with high biodegradability by utilizing nucleophilic reactions with sodium hydroxide $(\mathrm{NaOH})$ or with calcium hydroxide $\left(\mathrm{Ca}[\mathrm{OH}]_{2}\right)$ as hydrolyzing agents, thereby initiating complex competing reactions in which time and nucleophilic concentration influenced production of mono- and di-hydroxylated aromatic intermediates. $\mathrm{OH}^{-}$was added to TNT analogues TNB and picric acid. UV/Vis spectra revealed that TNT, TNB and picric acid share some time-dependent common 
intermediates that absorb in the visible region $(450 \mathrm{~nm})$ and later disappear, indicating a breaking of the aromatic ring, complete loss of aromaticity and, therefore, irreversible degradation [41-43, 50, 86]. $\mathrm{NaOH}$ and $\mathrm{Ca}(\mathrm{OH})_{2}$ added to TNT also resulted in loss of both UV and Vis absorption bands, strongly suggesting degradation to non-aromatic compounds - thus irreversible degradation. Although UV/Vis spectra did not reveal obvious loss of aromaticity, as in the case of $\mathrm{TNT}, \mathrm{OH}^{-}$added to picric acid formed, through different competing mechanisms, various ortho and para mono- and di-hydroxylated products - some of which can be expected to be biodegradable, similar to picric acid [41-43, 50, 86]. Due to competing mechanisms, in addition to possible formation of picric acid, other transformation products can be formed with the addition of $\mathrm{OH}^{-}$to $\mathrm{TNT}$ at $\mathrm{C} 3$ (nucleophilic substitution) or with the replacement of the nitro group by an $\mathrm{OH}^{-}$at $\mathrm{C} 2$ (via Meisenheimer complex intermediates).

Upon addition of an $\mathrm{OH}^{-}$group to TNP, another TNT analog, the UV spectra shifted from near 360 to close to $400 \mathrm{~nm}$. Both removal of the electron-withdrawing nitro group and addition of $\mathrm{OH}^{-}$caused a shift in the same direction toward a longer wavelength. Formation energies of the possible products of these competing reactions indicate the ease of their formation. Since the entropies of these compounds are similar - due to similar aromatic structures - these formation energies, in turn, are proportional to their Gibbs free energies and thus to their reactivity. $\mathrm{OH}^{-}$are more likely to attack the carbon $\mathrm{C}_{1}$ having the methyl group attached rather than the $\mathrm{C}_{2}$ having the nitro group attached, as energy calculations indicate the transition state product of $\mathrm{OH}^{-}$addition to the former as being less sterically

hindered $[41-43,50,86]$.

\subsubsection{Transformation mechanisms}

TNT reactions are governed by four effects: resonance, inductive, steric hindrance and intramolecular electrostatic interaction between the nitro group oxygen atoms and three methyl group hydrogen atoms. Nitro groups 2 and 6, adjacent to the methyl groups, are most subject to these four effects. They are the most sterically hindered by the methyl group, which inductively supplies them with electrons [41-43, 50, 86].

Although nitro groups deactivated all positions on the ring, Figure 2, the carbons ortho and para to the carbon having the nitro groups became the most deactivated through resonance stabilization, where the $\pi$ electrons are drawn away by resonance from these ortho and para carbons toward the nitro group outside the ring. This deactivation renders the carbons ortho and para to the nitro group susceptible to nucleophilic attack by $\mathrm{OH}^{-}$. This mechanism competes with formation of the Meisenheimer complex where the $\mathrm{OH}^{-}$attacks the carbon carrying the nitro group, causing brief formation of a transition state in which both nucleophile and nitro group are still attached to the same carbon before elimination of the nitro group [41-43, 49, 50, 86].

The presence of an $\mathrm{OH}^{-}$instead of the methyl group lowered steric hindrance sufficiently to facilitate removal of nitro groups - theoretically, according to our computations and textbook chemistry, good leaving groups in nucleophilic reactions [56, 79-85]. In March's prioritizing of effective leaving groups in nucleophilic reactions, nitro groups is listed as second, after fluorine [82]. These electrostatic interactions between the hydrogen atoms of the methyl group and the oxygen atoms of the ortho 2 nd and 6th position nitro groups prevent effective chemical transformations of TNT to 
DNT by electrophilic attack on the carbon bonded to the electron withdrawing nitro groups. Therefore, chemical transformations of TNT should be carried out using nucleophilic rather than electrophilic substitutions. In addition, nucleophilic transformations result in formation of more easily biodegraded hydroxylated nitro compounds, particularly when the two hydroxyl groups are ortho or para to each other [41-43, 50, 79-86].

\section{TNT}

Charge Density - showing the most deactivated carbon atoms

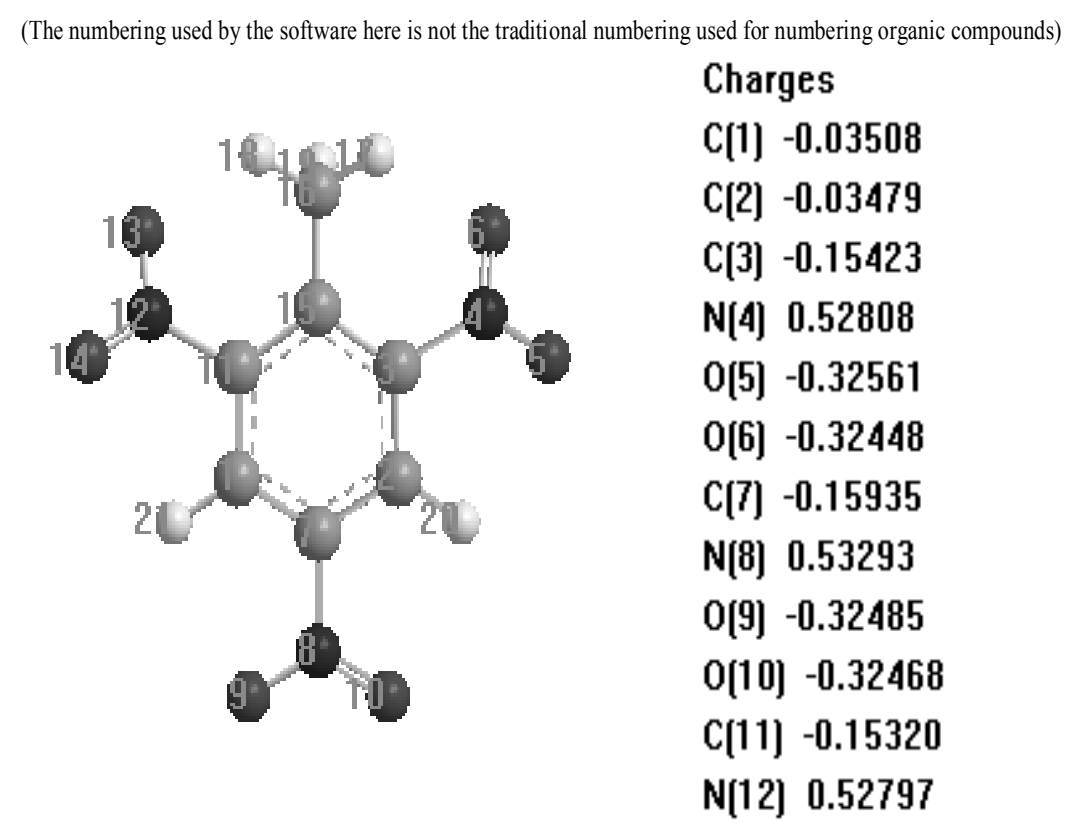

Figure 2. Charge Density of TNT.

Polymerization reactions constitute another competing mechanism and can occur at various sites on the TNT molecule. For example, upon loss of a proton from the methyl group carbon (proton abstraction resulting from high concentration of base) one TNT molecule can act as a nucleophile for another TNT molecule by attacking its positively charged atoms, thus forming a dimer $[41-43,50,79-86]$.

\subsubsection{Potential for toxic interactions}

Dimerization can also occur at different TNT molecular sites, such as between nitrogen atoms of two molecules or between one nitrogen atom from one molecule and a carbon from another [37]. Polymerization can cause creation of toxic compounds. For instance, some di-azo polymers of TNT can be expected to be as toxic as certain azo dyes. Further, in regard to toxicity, $\mathrm{OH}^{-}$groups render molecules to which they are attached more water soluble, thus facilitating metabolism. For instance, adding two adjacent $\mathrm{OH}^{-}$to benzene causes benzene to become sufficiently soluble to be metabolized by humans. Under certain conditions, the two adjacent $\mathrm{OH}^{-}$yield a water molecule and form an epoxy - benzene oxide - the cause of benzene's carcinogenicity. Due to its molecular structure, the same principles as to $\mathrm{OH}^{-}$contributing to solubility and to the occasional formation of an epoxy due to loss of a water molecule are also applicable to TNT. 
Two other factors relating to toxicity: ortho are generally more toxic than para substituted amines (Table1) [41-43, 50, 79-86]. Yet, two adjacent hydroxyl groups or two hydroxyl groups para to each other may cause the aromatic parent compound to decompose into smaller molecules less toxic than the parent.

Table 1. Energies and other Properties of TNT and Related Compounds.

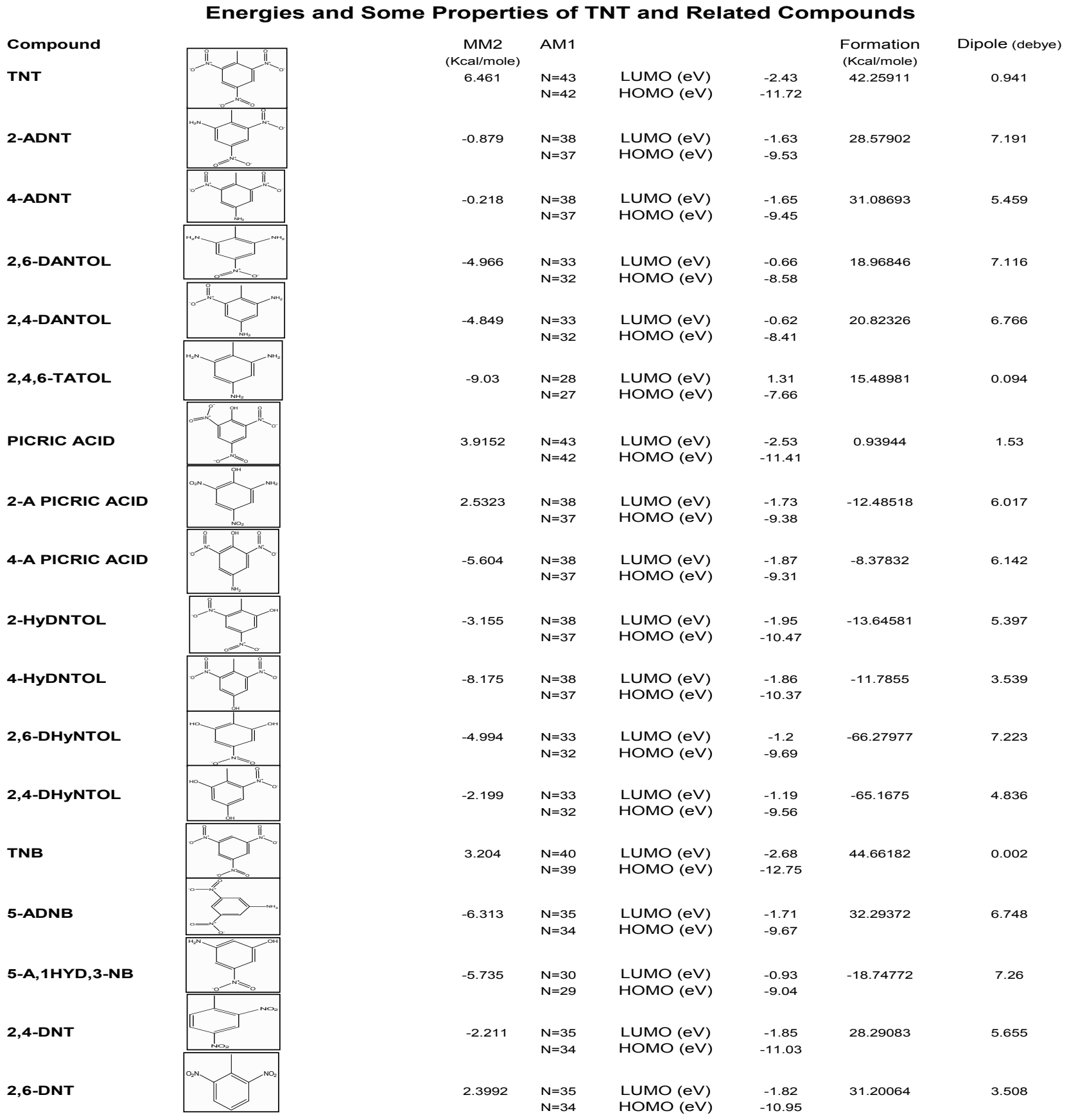

Haderlein asserted [68] that electron donor-acceptor interactions result in TNT reacting with soil and other natural organic materials in its environment, thus influencing its mobility, bioavailability, and reactivity - all of which impinge on toxicity levels. Although reactions of TNT with $\mathrm{OH}^{-}$have been analyzed, only fairly recently have investigations of TNT with $\mathrm{OH}^{-}$in aqueous solutions been 
considered as comprising or as partial potential treatment technology for TNT contaminated soils and groundwater [17, 21-22, 24-26, 29-30, 36-37, 39, 41-43, 48-51, 66-71, 76-77, 78]. Experimental data for hydrolysis of TNT in aqueous solutions - suggesting that alkali transformation of TNT takes place through formation of color-producing intermediates that are further transformed to non-aromatic compounds - have been reported at $\mathrm{pH} 12$ [41-43]. This reaction at $\mathrm{pH} 12$ is quite fast with $25 \mathrm{mg} / \mathrm{L}$ TNT transformed into non-aromatic compounds within six hours. Significant amounts of nitrite are also released, indicating that the resultant compounds are not only non-aromatic, but also less nitrated. The presence of nitro groups in the non-aromatic compounds, however, is not considered a drawback in light of the easy-leaving character of nitro-groups. Thus, oxidative attack on the exposed carbon backbone may even be enhanced by the electron-withdrawing nature of nitro-groups [41-43].

3.2 Selected TNT analogs-including TNB (1,3,5-trinitrobenzene) and TNP (2,4,6-trinitrophenolpicric acid)

\subsubsection{Results and mechanisms}

TNT and seventeen of its possible analogs were compared computationally in our first attempt to discover relationships between structure, reactivities and toxicity. Amino and hydroxyl groups were substituted at the 2,6 and 2,4 positions [86, 88]. Also, 2,6- and 2,4-dinitrotoluenes were included in the comparison as to formation, steric, HOMO/LUMO energies, and dipole moments. Significant correlations in relating structural changes to energy variations were obtained using both semiempirical (AM1) and DFT B3LYP computational approaches, which reflected the same trends [41-43, 50, 86-88].

Due to inductive, steric and electrostatic effects of the methyl groups, TNB has slightly higher heat of formation and lower steric energy (MM2, level 1) than TNT. MM2 for picric acid is only slightly lower than that of TNT (which has the highest MM2) - followed by picric acid (TNP) then TNB. Replacing the methyl group with an $\mathrm{OH}^{-}$considerably lowered the heat of formation. For example, addition of an $\mathrm{OH}^{-}$to form picric acid drives the heat of formation drastically lower than for both TNT and TNB. In comparison with TNT, TNP and TNB, TNB has the highest heat of formation but the lowest steric and HOMO and LUMO energies. However, the heat of formation became lower as more $\mathrm{OH}^{-}$groups were added. Heat of formation and HOMO and LUMO energies are consistent [41-43, 50, 86-88].

Both computational methods, AM1 and DFT consistently showed that substituting an amine for the TNT nitro group lowers both AM1 and MM2 energies (Table 1). AM1, MM2 and HOMO energies were always lower when the amine was substituted on the ortho $\mathrm{C}_{2}$ than on the para $\mathrm{C}_{4}$ position with respect to the methyl group, because amines add electrons to the aromatic ring, thereby activating them. This lowering of energy on the ortho position to the methyl group is due to both inductive and steric effect of the methyl group (Resonance effect is the same for both ortho and para positions). Furthermore, for each amine group substituted for a nitro group on TNT, the greater was the lowering of MM2 steric energy and heat of formation. For both mono and di substituted amino and hydroxyl groups, the steric and formation energies and HOMO were always lowest when the substitution was on the ortho rather than the para position. For example, 2-amino molecular energy is lower than that of 4- 
amino, and 2-hydroxy molecular energy is always lower than that of 4-hydroxy. The same trend pertains to di-amino and di-hydroxy substitutions on TNT. That is, 2,6-di-amino and 2,6-di-hydroxy are always lower than 2,4-di-amino and 2,4-di-hydroxy substitutions.

The TNT analogs 2,6- and 2,4-dinitrotoluene are equally affected by resonance. Therefore, the greater toxicity of 2,6- compared to that of 2,4-dinitrotoluene is attributed to 2,6-dinitrotoluene being subject to greater inductive, steric hindrance, and intramolecular bonding effects between the oxygen atoms of the nitro groups adjacent to the hydrogen atoms of the methyl group $[50,86]$. In other words, due to this intramolecular interaction, complexation with media is less when the amino group is substituted on the ortho position and is more available to the environment.

The more nitro groups are substituted by amino or hydroxyl groups, the higher the HOMO and LUMO energies will be and the lower will be the heat of formation. The most drastic lowering of the heat of formation occurs upon greatest hydroxyl group substitution (Table 1). The HOMO energy is lower when amines or hydroxyl groups are substituted at the ortho (2,6 ) rather than the para (4) position. This is true for both mono- and di- substitutions. For example, 2-amino- and 2-hydroxyl- are always of lower HOMO energy than 4-amino- and 4-hydroxyl-dinitrotoluene. Also 2,6-diamino- and 2,6-hydroxyl-nitrotoluene are always of lower HOMO and LUMO energy than 2,4- dinitro- and 2,4dihyroxyl-nitrotoluene. On the other hand, due to the electron withdrawing nature of the nitro groups, the trend is reversed with the dinitrotoluenes - the 2,4 dinitrotoluene always having lower HOMO, LUMO and formation energies than 2,6 dinitrotoluene [50, 86-88].

\section{Cyclic nitramines}

\subsection{RDX (hexahydro-1,3,5-trinitro-1,3,5-triazine)}

\subsubsection{Background}

It is general knowledge that RDX is a commonly used explosive whose production and widespread military and commercial use has resulted in extensive contamination of soil and groundwater. RDX is considered a possible class $\mathrm{C}$ carcinogen and also affects the central nervous system in mammals [14]. A number of efforts have been made to determine the fate of RDX in the environment and to develop technologies for remediation of RDX contaminated soil and groundwater, including thermal degradation; photo- and chemical oxidation/reduction; alkaline hydrolysis, adsorption, free radical and biodegradation [12, 18-19, 23, 31, 33-34, 38, 41, 46-48, 52, 55-56, 59, 72-74, 89-91]. Knowledge of molecular structure, transformation mechanisms and range of potential RDX intermediates and products is necessary to management of contaminated real estate, particularly where military personnel are involved.

\subsubsection{Structure}

RDX is a cyclic hexanitramine with alternating carbon and nitrogen atoms and with nitro groups bonded to the three ring-nitrogen atoms. The angles between the atoms in the cyclic ring are a "compromise" between the $109^{\circ}$ of tetrahedral compounds and the $120^{\circ}$ of cyclic hexagonal 
compounds, making RDX a non-planar compound, structurally similar to cyclohexane [55-56, 59, 78-85].

Analysis via classical mechanical calculations (force-field molecular dynamics) to determine steric hindrance energy revealed that among all its cyclic amino, cyclic nitroso and cyclic hydroxylamine derivatives, only RDX showed two distinct observable conformers with different stable geometries (of the trans - or "chair" - configuration) as shown by Qasim et al [90]. Repeated calculations indicated the existence of these two stable conformers only in the presence of the three RDX nitro-groups and not when three nitroso or three hydroxyl amines were substituted for these nitro groups. Although RDX is not planar, all three nitro groups are directed toward the same side of the molecule. This particular geometric configuration makes it possible for positive ions to electrostatically attract the oxygen atoms of the nitro groups, indicating that they become good leaving groups for nucleophilic reactions $[41,55-56,59,90]$.

The heat of formation, but not steric energy, is the same for both conformers. One conformer has steric, MM2, energy of about $12 \mathrm{Kcal} / \mathrm{mol}$ and the other has steric energy of about $-1.8 \mathrm{Kcal} / \mathrm{mol}$. Thus, based on MNDO and MM2 values, RDX can easily be reductively transformed into its mono-, di-and tri- nitroso-derivatives. The trinitroso and the trihydroxylamine derivatives are similar as to heat of formation, but the latter have less steric energy - indicating that further RDX transformations are more likely to proceed via the trihydroxylamine derivative $[41,55-56,59,90]$.

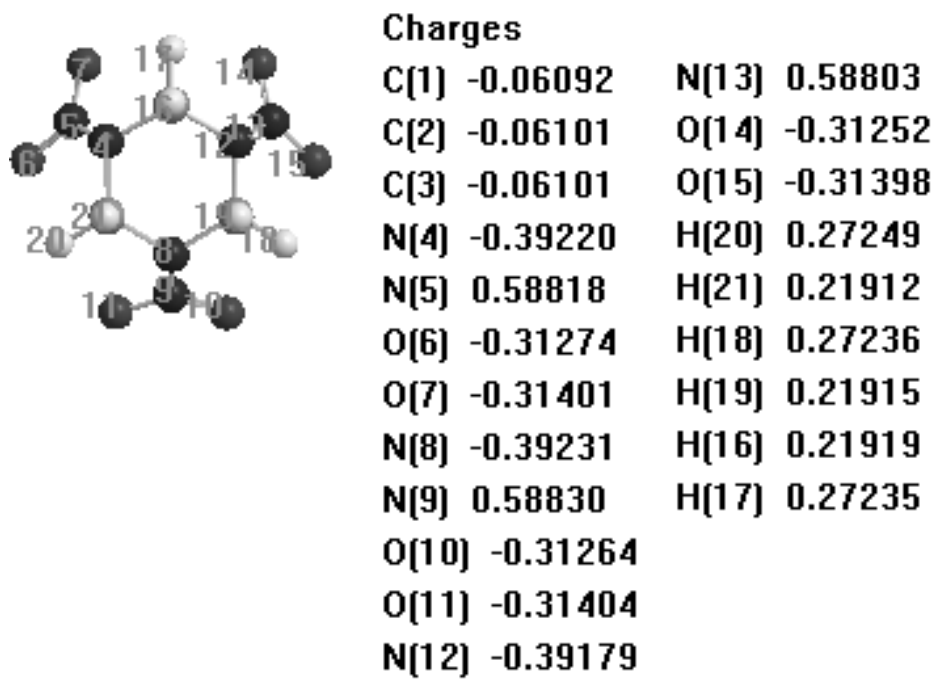

Figure 3. Charge Density of RDX.

\subsubsection{Differences between RDX and TNT}

According to CC energy calculations, RDX reduction, unlike that of TNT, stops with the formation of nitroso and unstable hydroxylamine derivatives [41, 59-60, 86, 90]. Since, unlike TNT, RDX is non-planar and non-aromatic, it lacks the resonance stability of its $\pi$ system. The nitro groups of RDX do not constitute an electron withdrawing sink-similar to that of TNT. Resonance, steric hindrance, strong intramolecular attraction between the hydrogen atoms of the methyl group and the oxygen atoms of the adjacent ortho nitro groups are factors that weaken the nitrogen-oxygen bonds of TNT- 
which explains why TNT forms aromatic amines as first-tier final derivative products. Nitroso and hydroxyl amines constitute the first-tier final derivative products of RDX. The oxygen atoms of the TNT nitro groups are more electronegatively charged than those of RDX. Molecular orbital calculations show that RDX hydroxyl amine derivatives have lower formation energies than their corresponding amines, whereas TNT amine derivatives have lower formation energies than their corresponding hydroxyl amines [41, 59-60, 86, 90]. Figures 2 and 3 show TNT and RDX charge densities, respectively.

RDX nitro groups are quite stable relative to oxidation and to acid hydrolysis. The most significant oxidants of RDX are those compounds which can generate hydroxyl radicals. Although not a typical oxidative, the hydroxyl radical has high oxidation potential [55-59].

\subsubsection{Modes of transformation}

Theoretical calculations [41, 55-56, 59, 90] reveal that, depending on reaction conditions, the predominant and competitive modes of transformation for RDX include utilization of:

i) Hydroxide ions - in which addition of base initiates nucleophilic substitution of nitro groups;

ii) Hydroxide ions - in which addition of base utilizes hydroxylation to initiate proton abstraction via second-order rate elimination $\left(\mathrm{E}_{2}\right)$;

iii) Reduction - consisting of both chemical (e.g, hydride ions, sodium hydrogen sulfite combined with zero valent iron) and biochemical degradation;

iv) Free radicals - necessitating the introduction of free radical producing agents, such as Fenton, ozone, hydrogen peroxide, zero valent iron and photochemically induced reactions.

In addition to the above modes of degradation, RDX transformation can be affected by such environmental conditions as the presence of other explosives; adsorption, binding capacity and complexation of media; also reactivities of proliferated transformation products.

The N-N and C-N bonds as well as the oxygen atoms on the nitro-groups are potential reactive sites on RDX molecules and are subject to chemical attack via nucleophile; proton abstraction; or free radical.

i) A nucleophile $\left(\mathrm{OH}^{-}\right)$can attack the $\mathrm{N}-\mathrm{N}$ bond between the ring-nitrogen and the nitro-group nitrogen, and replace the nitro-group with an $\mathrm{OH}^{-}[55-56,59,90]$.

ii) Proton abstraction by a base (or any other reducing group) changes the carbon-hydrogen $(\mathrm{C}-\mathrm{H}) \sigma$ bond to a $\pi$ bond - rendering the ring weaker and, thus, susceptible to subsequent transformation. Hydroxyl ion attack on the protons on ring carbons proceeds via a second-order $\mathrm{E}_{2}$ mechanism where a proton is abstracted and an adjacent nitro group is eliminated, changing the $\sigma$ to a $\pi$ bond - thus forming a double bond. This type of reaction depends on the concentration of both nucleophile/base and RDX [55-56, 59, 90]. Stopped Flow (SF) analysis of the reaction of RDX with $\mathrm{NaOH}$ is shown in Figure 4a-b, revealing steps of RDX alkaline hydrolysis degradation. 

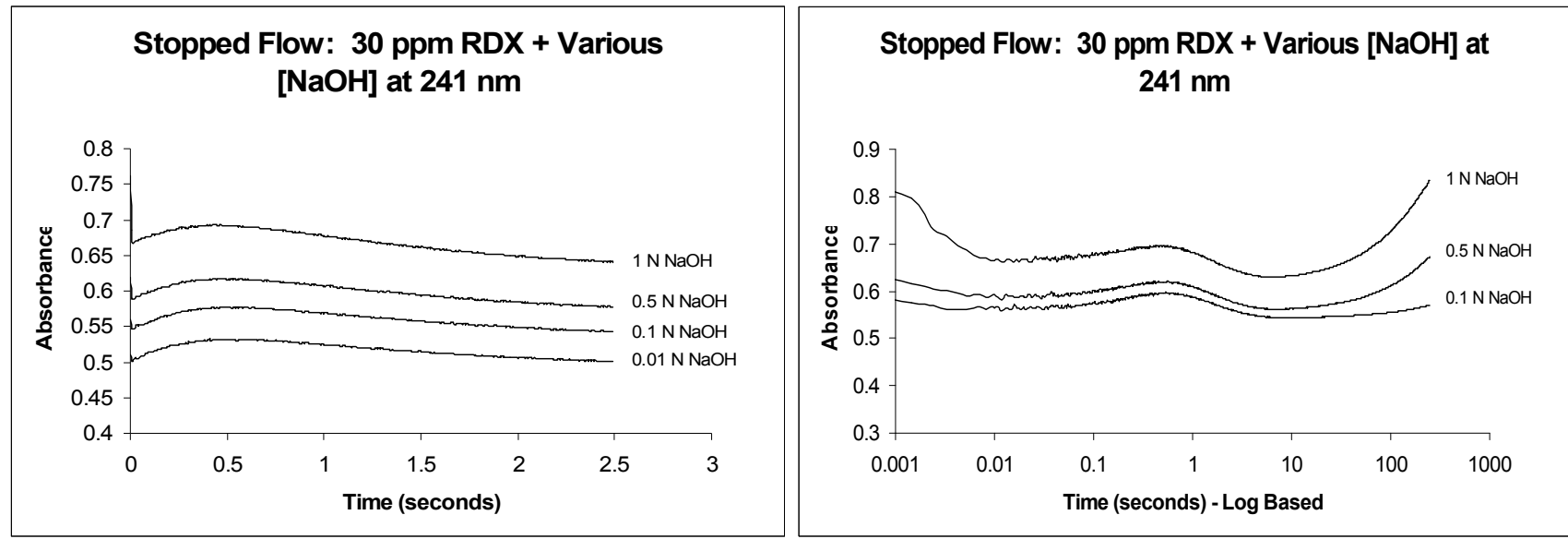

Figure 4a-b. Stopped-flow graphs of RDX with various concentrations of $\mathrm{NaOH}$ at $241 \mathrm{~nm}$.

Free radical attack on the N-N bond (iv) will also result in breaking this bond and will simultaneously generate two free radicals, one from the ring-nitrogen and the other from the nitrogen atom of the leaving nitro group. The $\mathrm{C}-\mathrm{N}$ bond between the ring nitrogen and the adjacent carbon atom can also be attacked by a free radical, thus also generating two free radicals. Two or more such bonds can break simultaneously via a concerted mechanism. The $\mathrm{C}-\mathrm{N}$ bonds in RDX are the longest bonds in the molecule and, therefore, are weakest and quite susceptible to free-radical attack. Although nitrous oxide $\left(\mathrm{N}_{2} \mathrm{O}\right)$ can also be formed in later steps by a combination of two nitrite free radicals, the appearance of nitrogen gas or $\mathrm{N}_{2} \mathrm{O}$ among the final products is an indication that the fragmentation most likely is not taking place at the N-N bonds between the heterocyclic ring and the nitro groups [55-56, 59, 90]. More transformation steps are shown for RDX than for HMX. Differences between these compounds are discussed under HMX.

\subsubsection{Transformation reactions}

RDX behaves as a strong Lewis acid, reacting with electron-donating compounds - such as hydroxide or hydride ions that act as base or as nucleophile depending on conditions of the reactions via either nucleophilic attack or the $\mathrm{E}_{2}$ mechanism, where proton abstraction and formation of double bonds takes place [59]. With the $\mathrm{E}_{2}$ mechanism, the base attack results in a transition state in which bond-breaking and bond-making happen concurrently. Proton extraction and breaking the $\sigma$ bond between the ring carbon and hydrogen take place at the same time as the formation of the $\pi$ bond between the ring carbon and ring nitrogen atoms. In other words, hydrogen abstraction occurs from the back while formation of the $\pi$ bond occurs simultaneously from the front. Experimentally, it was shown that the tendency toward the $\mathrm{E}_{2}$ mechanism is dependent on both alkali and RDX concentration. Both nucleophilic replacement of the nitro groups and/or base proton abstraction via the $\mathrm{E}_{2}$ mechanism cause the RDX molecule to become unstable and thus amenable to transformation [55-56, 59, 90].

First tier reductive chemical and biochemical degradation of RDX nitro groups leads to the formation of nitroso and hydroxylamine derivatives. Many second- and third-tier transformation products of RDX have been predicted and their energies and other properties calculated [41, 55-56, 59, 90]. The derived reduction scheme shows that substituted amines do not occur. Competition between the various modes of reaction drives the formation of final products [59]. 
Free radical oxidation reactions - in which symmetrical bond-breaking and cleavage takes placeoccur upon addition of hydroxyl (or other, e. g., hydroperoxide) radicals. These free radical oxidation reactions break the $\mathrm{C}-\mathrm{N}$ bonds symmetrically through sequential or concerted mechanisms [55-56, 59, 90]. Cyclic amines have the lowest MM2 energies and therefore, if formed, could be expected to be the least sterically hindered of the RDX transformation products. Only a single stable structure is predicted for such derivatives of RDX as trinitroso and trihydroxylamine. Further, RDX can be easily transformed into its trinitroso-derivative [55-56, 59, 90].

Preliminary calculations predict that in symmetrical bond breaking, the free radical mechanism is more apt to predominate upon increase in number of symmetrical (N-N for RDX and HMX, C-C for CL-20) bonds contained within the molecule. Free radical reactions are generally most apt to take place where bonds are between the same types of atom. The less polar bonds have a greater tendency toward free radical bond-breaking. Therefore, the higher the ratio of symmetrical bonds the more likely it is that transformation will proceed via free radical oxidation, as reflected by the comparison between lower HOMO/LUMO molecular orbitals of the cyclic nitramine derivatives. Also, the more strained the molecular structure, the greater is the tendency toward free radical bond-breaking via intersystem crossing to the triplet state-where changes in molecular geometry relieve strain [55-56, 59, 90].

In summary, because under similar conditions, the free radical ring-breaking pathway competes effectively with nucleophilic/base degradation, transformation mechanisms for C-N bond breaking can tend toward either free radical cleavage or toward nucleophilic/base abstraction. An additional factor contributing to free radical bond-breaking is steric hindrance due to molecular strain —where high MM2 values obtain [55-56, 59, 90].

Protonation of the oxygen atom on the nitro-group, followed by the loss of a water molecule will first transform the nitro-group into a nitroso group, and then into the less stable hydroxylamine derivative where the nitroso group exists in equilibrium with the hydroxylamine derivative in aqueous solution. This is followed by further transformation of the molecule via a concerted mechanism $[55-56,59,90]$.

Considerations pertaining to toxicity will be discussed after comparisons between RDX and HMX.

\subsection{HMX (octahydro-1,3,5,7-tetranitro-1,3,5,7-tetrazocine)}

\subsubsection{Background}

Her Majesty's Explosive, HMX, has been compared to its cyclic nitramine "sister," RDX, as to structure and reactivities [19, 27-28, 56, 59, 74, 94-95]. Questions as to environmental risk-fate, transport, toxicity, including hazard to personnel-have lead to HMX transformation studies. These studies have involved both experimental and CC methods.

\subsubsection{Structure}

HMX is an eight-member alternating nitrogen-carbon ring, whereas RDX is a six-member alternating nitrogen-carbon ring. 
Computer predictive methods to ascertain structure and transformations of HMX include the four competitive modes of degradation that pertain to RDX: i) hydroxide ions - addition of base utilizes hydroxylation to initiate proton abstraction via second-order rate elimination $\left(\mathrm{E}_{2}\right)$; ii) hydroxide ionsaddition of base initiates nucleophilic substitution of nitro groups; iii) reduction-both chemical and biochemical degradation; iv) free radicals - introduction of free radical producing agents as: Fenton, ozone, hydrogen peroxide, zero valent iron and photochemically induced reactions [56, 59, 93-95]. Although the chemical structure of HMX is similar to that of RDX, more comprehensive studies are needed to account for the differences between these similar compounds. (Results of semiempirical calculations compare HMX to RDX in Table 2. HMX is compared to cyclic and cage cyclic nitramines as well as to the nitrocubane, ONC, in Figure 1.)

\subsubsection{Transformation mechanisms}

Our calculations of RDX and HMX charge densities (Figures 3 and 5, respectively) comprise an attempt to discover differences between RDX and HMX: i) RDX nitro group oxygen atoms are more negatively charged than those of HMX. ii) The nitro group nitrogen atoms of both RDX and HMX are positively charged. However, RDX nitro group nitrogen atoms are less positive than those of HMX. iii) The RDX ring nitrogen atoms are less negatively charged than those of HMX. iv) The carbon atoms of both RDX and HMX are almost neutral, with RDX carbons being slightly less than zero while HMX carbons being slightly positive.

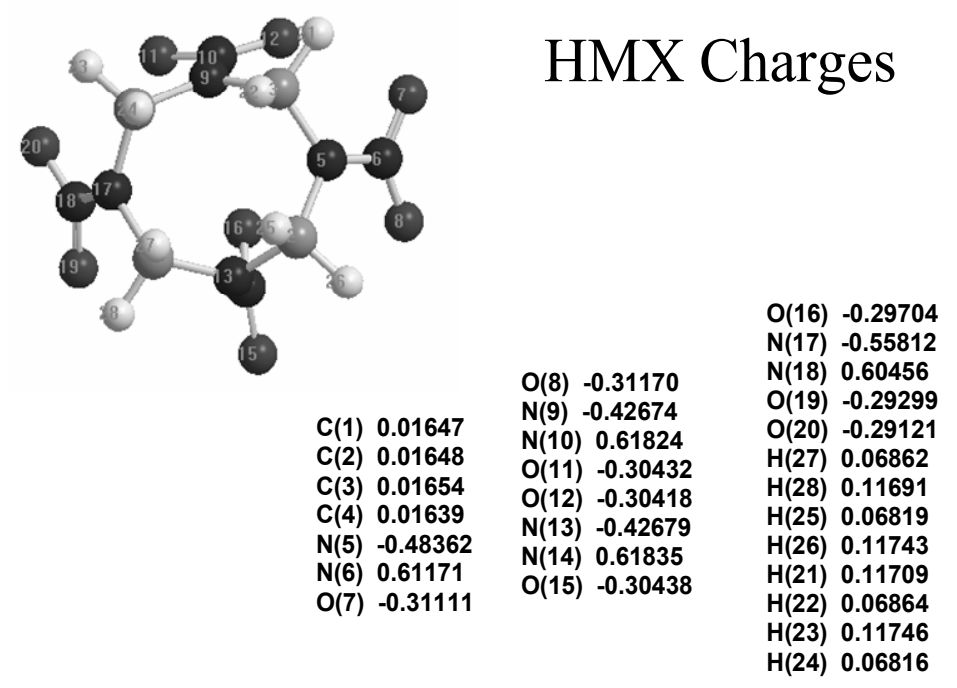

Figure 5. Charge Density of HMX.

In comparing charge densities of RDX and HMX (Figures 3 and 5) with those of TNT (Figure 2), the TNT nitro group oxygen atoms are more negatively charged than those of RDX which, in turn, are more negatively charged than those of HMX. This may be a reason that: under certain reductive conditions, nitroaromatic compounds will be reduced to their corresponding amines, whereas RDX and especially HMX will be reduced to their corresponding nitro and hydroxyl amines (but not completely to amines). This is suggested by RDX and HMX formation energies [56, 59]. 
Table 2. Comparison of HMX and RDX via Semiempirical methods of calculation.

\begin{tabular}{|c|c|c|c|c|c|c|}
\hline \multicolumn{2}{|c|}{ Seic andFomation Energies $=k a d / m d e ; L U M a n d H O N=e V$} & & & & & \\
\hline Heds of Fomation & & $\underline{\mathrm{AM}}$ & MND & $\underline{\mathrm{PMB}}$ & & \\
\hline $\mathrm{AM}=1429591$ & LMO & -1.1188 & -1.046 & -0.8635 & $\mathrm{~N}=57$ & \\
\hline $\mathrm{MNO}=146.6710$ & HOMD & -11.7305 & -121415 & -113642 & $\mathrm{~N}=56$ & \\
\hline \multicolumn{7}{|l|}{$\mathrm{PMB}=589006$} \\
\hline Steric Enery $(M M)=$ & 0.4457 & & pipdeMbment & $=10.482$ & & HMX \\
\hline \multicolumn{7}{|c|}{ HMReductionProduts-FistTier } \\
\hline \multicolumn{7}{|c|}{ HMX-Mboritroso } \\
\hline Hets of Formation & & $\mathrm{AMl}$ & MND & $\mathrm{PMB}$ & & \\
\hline $\mathrm{AM}=125.620$ & LMD & -0.866 & -0.887 & -0.8179 & $\mathrm{~N}=54$ & \\
\hline $\mathrm{MNO}=118.6010$ & HOMD & -11.2678 & -11.5792 & -10.685 & $\mathrm{~N}=53$ & \\
\hline \multicolumn{7}{|l|}{$\mathrm{PMB}=74.5536$} \\
\hline \multicolumn{3}{|c|}{$\underline{\text { Seric Energ }(M M)}=228973$} & \multicolumn{3}{|c|}{ DipdeMbnent $=10.176$} & bnonitroso \\
\hline \multicolumn{7}{|c|}{ HMX-Mbrohydroxylamine } \\
\hline Heds of Fomation & & $\mathrm{AMl}$ & MND & PMB & & \\
\hline $\mathrm{AM}=119.2545$ & LMO & -0.9456 & -0.8289 & -05623 & $\mathrm{~N}=55$ & \\
\hline $\mathrm{MNO}=1173785$ & HOMO & -10.219 & -11.3209 & -105506 & $\mathrm{~N}=54$ & \\
\hline $\mathrm{PMB}=587301$ & & & jpodeMbrten & $=8329$ & & \\
\hline Steric Energy $(M M)=$ & 3995 & & & & & ylanine \\
\hline
\end{tabular}

\section{RDX-APPROXMATIONMEIHODSOFCALCULATION}

Steric and Formation Energies =kcalmml; LUMOar and $\mathrm{Hb} m=e \mathrm{~V}$

\begin{tabular}{|c|c|c|c|c|c|}
\hline Heats of Formation & $\mathbf{R D X}$ & AM1 & MND & PMB & \\
\hline $\mathrm{AMI}=1048850$ & LUMO & -1.1008 & -1.0978 & -02168 & $\mathrm{~N}=43$ \\
\hline $\mathrm{MDO}=1008966$ & HOMO & -121057 & -123302 & -11.0842 & $\mathrm{~N}=42$ \\
\hline \multicolumn{6}{|l|}{$\mathrm{AMB}=421098$} \\
\hline ericEnergy (MNR & & & & & \\
\hline
\end{tabular}

RDXReduction Products--First Tier

RDX-Mononitroso

$\begin{array}{llrrrr}\text { Heats of Formation } & & \underline{\mathrm{AM}} & \underline{\mathrm{MND}} & \underline{\mathrm{AMB}} & \\ \mathrm{AMM}=88.8247 & \text { LUMO } & -0.8675 & -0.8998 & -06856 & \mathrm{~N}=40 \\ \mathrm{MND}=73.3264 & \text { HOMO } & -11.3769 & -11.6232 & -106531 & \mathrm{~N}=39 \\ \mathrm{AMB}=563635 & & & & & \end{array}$

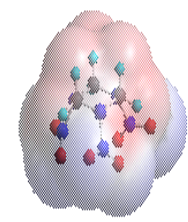

$1 \mathrm{RDX}$

StericEnergy $(\mathbf{M M R})=\{\quad 8.6644$ Dpde Moment $=6398$ Lebye

RDX-Mondhydroxylamine

\begin{tabular}{|c|c|c|c|c|c|}
\hline Heats of Formation & & AMI & MND & $\mathrm{PMB}$ & \\
\hline $\mathrm{AM}=89.610$ & LUMO & $-0.5 / 2$ & -0.6948 & -0.352 & $\mathrm{~N}=41$ \\
\hline $\mathrm{MDO}=728219$ & HOMO & -11.0252 & -11.295 & -10.745 & $\mathrm{~N}=40$ \\
\hline
\end{tabular}

$A B=39933$

2755 Dpde Moment $=6803$ Debye

Further comparing RDX and HMX, as well as their respective first tier reductive mononitroso and monohydroxylamine derivatives: the HMX structure has a higher heat of formation than that of RDX, which is to be expected as RDX is a smaller molecule. Using semiempirical methods of calculation, AM1, MNDO, PM3, and considering HOMO/LUMO energies, it was found that the heats of formation not only for HMX, but also its corresponding mononitroso and monohydroxylamine derivatives are 
higher than for the corresponding mononitroso and monohydroxylamine derivatives of RDX. Also, mononitroso and monohydroxylamine heats of formation are comparable to each other-both in HMX and in RDX [56-59].

Due to its size, the degradation of HMX is slower than that of RDX and is expected to show a slower disappearance in most media than RDX. (According to Heilmann et al, HMX disappearance via alkali hydrolysis is ten times slower than that of RDX [30]). HOMO energies of RDX and its mononitroso and monohydroxylamine derivatives are shown to be more negative (have lower values) than HMX and its mononitroso and monohydroxylamine derivatives. Also, HOMO energies are lower for HMX and RDX than for their respective mononitroso and monohydroxylamine derivatives $[56,59]$.

Moreover, both HMX and RDX are unlikely to form amine derivatives as TNT and other aromatic compounds tend to do. Being planar, aromatic compounds have intramolecular attraction between the hydrogen atoms of the methyl group and the ortho oxygen atoms of their adjacent nitro groups. The oxygen atoms on aromatic compounds are more electronegative and, therefore, the nitro groups tend to be reduced in steps to amines by addition of six protons, six electrons and loss of two water molecules. Aromatic nitro group oxygen atoms are more electronegatively charged than those of RDX. More importantly, RDX and HMX do not possess the $\pi$ system and resonance stability that aromatic compounds do. These characteristics enable aromatic compounds to form an amine derivative, which RDX and HMX never reach, as they tend to degrade as nitroso and monohydroxylamine products $[56,59,78-85]$.

Stopped Flow analysis of HMX combined with $\mathrm{NaOH}$ shows the slow formation followed by the slow disappearance of a product in two steps. Stopped Flow data confirms that HMX is less reactive than RDX to alkaline hydrolysis [56, 59].
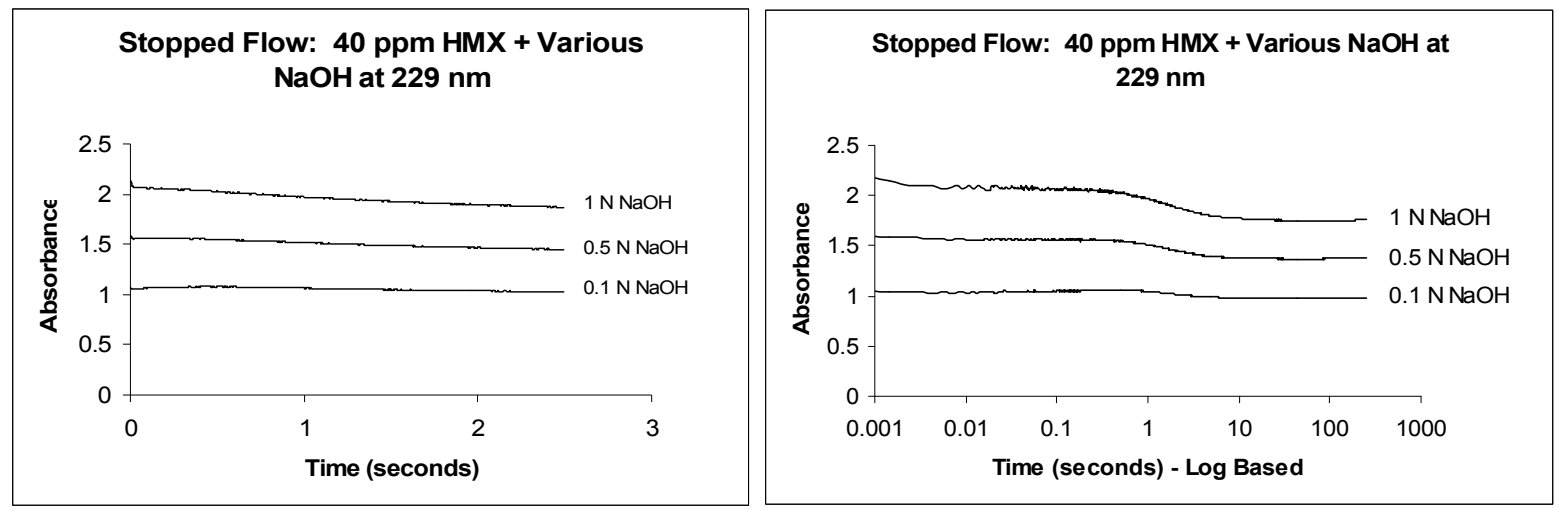

Figure 6a-b. Stopped flow graphs of HMX with various concentrations of $\mathrm{NaOH}$ at $229 \mathrm{~nm}$.

\subsubsection{Toxicity considerations}

RDX and HMX are less apt to bind to media than TNT. Therefore, their dispersal into the environment and potential for toxic environmental interactions are expected to be greater. It is assumed, especially in the case of RDX, that conjugated $\pi$ bonds may occur in its transformation products under high alkaline conditions. Therefore, because the $\mathrm{E}_{2}$ mechanism may become dominant over the substitution mechanism, transformation to small molecules may be hindered. 
RDX and HMX do not polymerize, as TNT can under certain circumstances, thus precluding environmental interaction due to polymerization.

\section{$5 \quad$ Cage cyclic nitramines}

\subsection{CL-20 (2,4,6,8,10,12-hexanitrohexa-azoisowurtzitane)}

\subsubsection{Background}

CL-20 is a fairly recently synthesized NOC [97-100] and represents a newer generation of energetics expected to replace, at least partially, such older explosives as RDX and HMX in various applications. There is much current interest in the environmental interactions of CL-20 and its transformation derivatives as well as concern regarding environmental hazards, including potential harm to personnel. (For example, CL-20 was shown to be as toxic as nerve gas to segmented and nonsegmented worms [15].) Due to: CL-20 toxicity; the recalcitrance and toxicity of at least one degradation intermediate [57-58, 60, 63-65, 101]; and to CL-20's potential usefulness - which should lead to its expanded presence in the environment - understanding the fate, transport and effects of CL$20[3,5-6]$ and its transformation derivatives is essential.

Examples of recent CL-20 research show a variety of approaches: photodegradation [3]; degradation in subsurface environments [5-6]; degradation through alkali hydrolysis [19, 57-58, 60, 63-65, 101] biochemical degradation [45]; decomposition through use of iron [20]; comparisons with RDX as to structure and possible degradation pathways [84-86]; and predictive comparisons of cyclic and cage cyclic nitramines plus other computational approaches [55-58, 60, 63-65, 86-87, 93, 96].

\subsubsection{Structure}

The first structural studies came out of China Lake where CL-20 was synthesized [97-100]. Later studies compared the cyclic nitramine, RDX, and new cage cyclic nitramine, CL-20, structurally, to ascertain possible similarities/differences in behavior $[19,55-56,86]$. RDX and CL-20 degradation pathways were compared through results of MOPAC quantum chemical methods and classical force field mechanics [55-56].

As to geometrical structure, the $\mathrm{CH}-\mathrm{N}-\mathrm{NO}_{2}$ bonds are common to both compounds. However, CL20 is more complex than RDX due to the presence of its three $\mathrm{C}-\mathrm{C}$ bonds, causing CL-20 to be more symmetrical and less polar. The "attic" bond joining the two cyclopentane rings and the two base bonds on opposite sides of the cyclohexane ring comprise these bonds. CL-20 is more sterically strained, has higher formation energy, and is denser than RDX [55-56, 86]. At first glance, the highly strained nature of the CL-20 molecule suggests that initial transformation reactions could be relatively rapid compared to those of RDX. Yet, CL-20's greater structural complexities, and SF rate calculations, indicated that complete transformation is expected to be slower than that of RDX [55-56, 86]. Also, MOPAC energy calculations suggested RDX degradation to be less difficult than that of CL-20 due to the former involving fewer steps. Polarity and other features of CL-20 and RDX are compared in Figure 7. CL-20 bond lengths and charges in Figure 8 reveal that the C-C bonds are more stretched and longer than other bonds - to relieve molecular strain. 


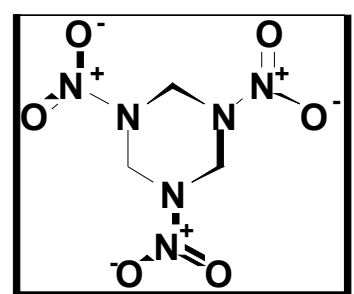

RDX

$\mathrm{C}_{3} \mathrm{H}_{6} \mathrm{~N}_{6} \mathrm{O}_{6}$

Ex ac t M a ss: 222.03

Mol. Wt.: 222.12

C, 16. 22; H, 2.72; N, $37.84 ; 0,43.22$

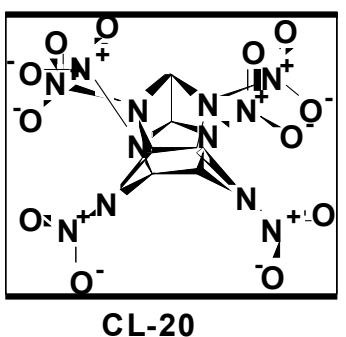

$\mathrm{C}_{10} \mathrm{H}_{22} \mathrm{~N}_{12} \mathrm{O}_{12}$

Exa ct $M$ as s: 502.15

Mol. Wt .: 502.36

C, $23.91 ; \mathrm{H}, 4.41$; N, $33.46 ; \mathrm{O}, 38.22$

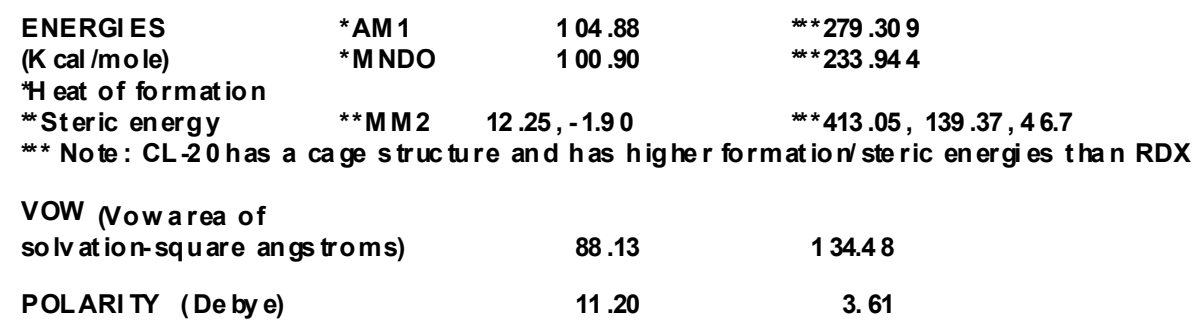

STR UCTURAL SIMILARITIES :

R DX: 3 NO 2 groups bonde $d$ to $3 c$ yc lic al tern at ing $N$

CL-20: 6 NO 2 groups

on 6 cy cli $\mathrm{cN}$

(1. 35 angstroms)

BON DING DI FFERENCES

R DX: no C-C bonds

CL-20:3 C-C bonds

$3 \mathrm{~N}-\mathrm{N} 1.40 \mathrm{~A}$ bonds

(1.55 $\AA$ )

6 C-N 1.49 A bonds

Typical 1.46 A C-N bonds

SITES OF REAC TIVITIES

FREE RADI CAL, OXIDATIO N, B OTH RD X AND CL -20

RDX: more at C-N bonds

Le ss at $\mathrm{N}-\mathrm{N}$ bonds

$\mathrm{CL}-20$ : at $\mathrm{C}-\mathrm{C}$ bonds, at $\mathrm{N}-\mathrm{N}$,

REDUCTION

RDX: at $n$ itro groups CL-20: at nitro groups

Figure 7. Comparisons between RDX and CL-20.

\subsubsection{Degradation mechanisms}

As with both TNT and RDX, CL-20 exhibits the same predominant and competitive modes of degradation that, again, depend on reaction conditions: i) addition of base utilizes hydroxylation to initiate proton abstraction via $\mathrm{E}_{2}$; ii) addition of base initiates nucleophilic substitution of nitro groups; iii) chemical and biochemical reduction; and iv) introduction of free radical producing agents to induce reactions $[55-58,86]$.

It is more likely that the free radical symmetrical bond-breaking mechanism will occur with increase in number of symmetrical $\mathrm{C}-\mathrm{C}$ bonds contained within the molecule. As with RDX, symmetrical bond breaking may occur simultaneously or sequentially [55-58]. Moreover, less polar 
bonds have greater predisposition toward free radical bond breaking. Thus, under similar conditions, the higher the ratio of $\mathrm{C}-\mathrm{C}$ bonds, the more likely it is that degradation will proceed via free radical oxidation. This is reflected in lower HOMO/LUMO energies, [55-58]. In addition, the more strained the molecular structure is, the greater is the affinity for free radical bond breaking via intersystem crossing to the triplet state, where changes in molecular geometry occur [55-58].

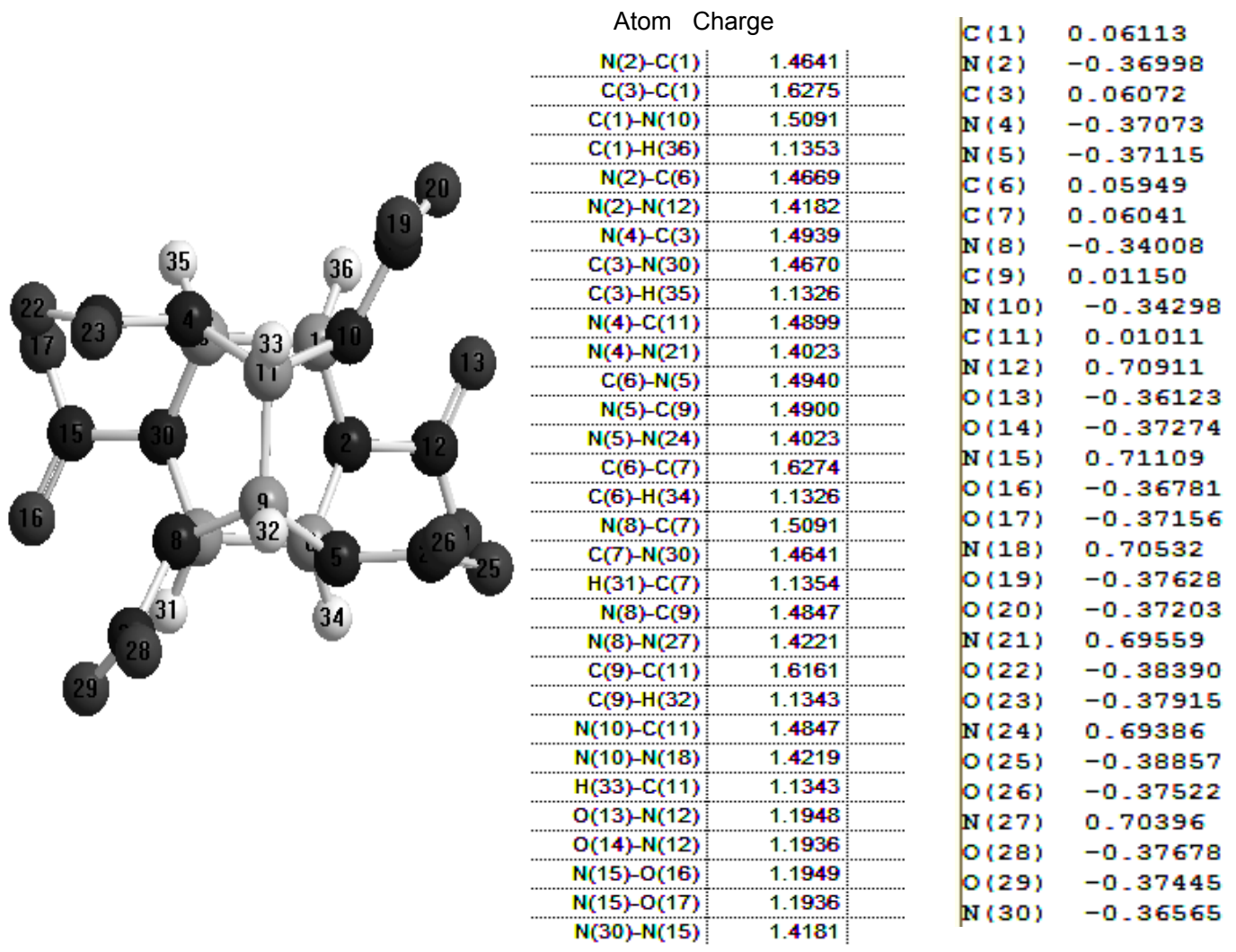

Figure 8. CL-20 Charge Density.

\subsubsection{Transformation via alkali hydrolysis}

MOPAC [57-58], then DFT [63-65] computational studies identified the most likely CL-20 transformation pathway and also predicted most likely transition states and intermediates. The lowestenergy sequence of intermediates appears to constitute the pathway followed during CL-20 alkaline hydrolysis. As computationally predicted, the preferred bond-breaking is through the bond joining the "attic" peaks of the two clyclopentane rings and sequential peeling of the nitro groups. MOPAC theoretical studies [56-58] also unexpectedly predicted formation of an alkali hydrolysis CL-20 aromatic transformation product appearing more recalcitrant and toxic than the parent due to the removal of the nitro groups and formation of a conjugated $\pi$ system [56-58]. Szecsody's findings [5-6] were consistent with these predictions. Okovyty [63, 65] and Kholod's [64] DFT computational studies corroborated this resulting three-member ring pyrazine product, 1,3,4,5,7,8hexanitrododedahydroiimidazo[4,5-b;4',5'-e]pyrazine, as having low formation and force field energies. Bond-breaking results in the stretching of the other two $\mathrm{C}-\mathrm{C}$ bonds and also in stretching the 
nitro group ring $\mathrm{N}-\mathrm{N}$ bonds. Either $\mathrm{OH}^{-}$replaces the nitro groups or (preferred pathway) they abstract protons and eliminate nitro groups via the $\mathrm{E}_{2}$ mechanism [58]. Since calculations reveal that CL-20 competing transformation mechanisms and intermediate products depend on numbers and sites of C-C bond-breaking, manipulation of $\mathrm{C}-\mathrm{C}$ bond-breaking - to change preferred degradation pathways and make a less preferred mechanism dominant — can be accomplished [57-58].

Spectroscopically obtained data confirmed CL-20 first-tier transformation products due to two competing modes of degradation through reactions due to addition of $\mathrm{OH}^{-}$and, in a different set of experiments, photo-induced free radicals. UV/VIS measured concentrations and followed the course of reactions while Stopped Flow (SF) followed the rates of CL-20 degradation to fast-forming transition states and intermediate products. FTIR followed CL-20 degradation through alkali hydrolysis, measuring changes in functional groups - nitro and amino as well as $\mathrm{C}-\mathrm{C}$ and $\mathrm{C}-\mathrm{N}$ bonds, thus indicating the breaking and formation of bonds as they occurred. Different compounds resulted, depending on which $\mathrm{C}-\mathrm{C}$ bond broke [57-58].

FTIR data [101] revealed that at lower $\mathrm{OH}^{-}$concentrations (less than 2:1 molar ratio of $\mathrm{OH}^{-}$to $\mathrm{CL}$ 20), the resulting $\mathrm{C}-\mathrm{H}$ bond stretch was most aliphatic (less than $3000 \mathrm{~cm}^{-1}$ ) while at higher $\mathrm{OH}^{-}$ concentrations $(1.0 \mathrm{~N}: 1000 \mathrm{ppm}$ of CL-20) the FTIR spectra revealed that most of the C-H stretch was greater than $3000 \mathrm{~cm}^{-1}$, indicating the formation of an aromatic intermediate with a C-C bond-similar to the TNT FTIR spectra [58]. FTIR data indicated a decrease in C-N intensity at $1049 \mathrm{~cm}^{-1}$. When reacted with high concentrations of $\mathrm{OH}^{-}$both UV and FTIR spectra of CL-20, strongly suggested the formation of an aromatic three-ring intermediate, 1,5-dihydrodiimidazo[4,5:4'5'-e]pyrazine. Formation of this aromatic structure is strongly supported by such UV/VIS spectral characteristics as the intense yellow-green $(375 \mathrm{~nm})$ color appearing when $1: 1$ by volume of $1.0 \mathrm{~N} \mathrm{NaOH}$ was added to 1000 ppm of CL-20 in dichloromethane. The FTIR spectra were obtained from the evaporated organic phase, whereas the UV/Vis spectra were obtained from the aqueous phase.

Both pyrazine compounds are corroborated in the DFT studies of Okovytyy [63, 65] and Kholod [64]. UV spectra revealed a concentration-dependent shift toward longer wavelengths upon addition of $\mathrm{OH}^{-}$, suggesting sequential removal of nitro groups and formation of double bonds until the aromatic compound, 1,5-dihydrodiimidazo[4,5:4'5'-e]pyrazine, was formed [59]. However, upon further addition of $\mathrm{OH}^{-}$, an abrupt shift to shorter wavelengths occurred, suggesting a breaking of the 1,5dihydrodiimidazo[4,5:4'5'-e]pyrazine into smaller aromatic compounds.

Breaking the other two $\mathrm{C}-\mathrm{C}$ bonds of the cyclohexane ring resulted in different, less important nonaromatic cyclic competing products of CL-20. Also, simultaneous breaking of both base C-C bonds results in a bi-cycloheptagonal ring intermediate, whereas breaking either of the base $\mathrm{C}$ - $\mathrm{C}$ bonds resulted in a compound consisting of two opposing cycloheptagonal rings, a cyclononagonal, and a cyclopentagonal ring [58-59].

\subsubsection{Transformation via free radical reactions}

Free radical reactions were photo-induced through irradiation at wavelengths of maximum absorption $(236 \mathrm{~nm})$ via a monochromatic irradiation system. Calculations indicated [58-59] that the free radical mechanism is more apt to occur upon increase in number of symmetrical $\mathrm{C}-\mathrm{C}$ (preferred) then N-N bonds contained within the molecule. Calculations indicated that the less polar the CL-20 
bond is, the greater is the tendency toward free radical bond-breaking. As with RDX, bond-breaking can be either sequential or simultaneous [84-86]. Low HOMO/LUMO values indicated that predicted free radical C-C symmetrical bond-breaking degradation prevailed-probably via intersystem crossing to a triplet state, where bond strain was eased through changes in geometry, bond-breaking and formation of intermediates [58-59].

\subsubsection{Potential toxicity}

Problems in assessing the toxicity of CL-20 and its intermediates in the environment are as great as the variety of possible reactive transitions. Also, transformation processes that may work in one minienvironment may not work in another due to either apparent or obscure differences that cannot be controlled.

Degradation processes, themselves, such as those producing free-radicals, may contribute to toxicity in the short run while producing desirable long term results. Free radicals are reactive and as such can affect type and degree of toxicity. Thus, non-ionic environmental media containing free radical inducing compounds (e.g., hydrogen peroxide, zero valent iron), also the presence of ultraviolet and visible light, can be expected to affect toxicity within the environment.

\subsection{ONC (octonitrocubane)}

Although categorized as a cage cyclic nitro energetic, $\mathrm{ONC}$ is not a nitramine since it has no amine. ONC has not yet been used as an explosive, and TNTAC has yet to be synthesized. However, their degradation mechanisms have been examined theoretically through both quantum and classical mechanics $[55-56,60,86]$ and are compared to cage nitramines in Figure 1.

\subsubsection{Structure}

Of the compounds studied, only CL-20 and ONC have C-C bonds (Figure 1). ONC has twelve C-C and no N-N bonds. Since C-C bonds comprise the ONC cage, ONC is the most non-polar of the cage cyclic nitro compounds, and it is predicted that the free-radical $\mathrm{C}-\mathrm{C}$ symmetrical bond-breaking degradation mechanism will prevail as indicated by low HOMO/LUMO values. This bond-breaking by a free radical mechanism may occur sequentially or simultaneously. Our energy calculations show that additional reactivity sites result at ONC bonds (as they do in CL-20) where stretching, symmetrical bond-breaking via intersystem-crossing to a triplet state, and production of intermediates occur [5556]. This stretching and symmetrical bond-breaking of the cage bonds alleviates bond strain. An additional factor contributing to ease of free radical bond-breaking in ONC is steric hindrance due to molecular strain — where extremely high MM2 values occur.

Being non-polar and highly crowded with nitro groups, the main ONC sites of reactivity are the: cage $\mathrm{C}-\mathrm{C}$ bonds; bonds between the cage carbon atoms; nitrogen atoms of the nitro groups; and, lastly, oxygen atoms of the nitro groups. Four ONC derivatives were studied via AM1 and MNDO [55-56], revealing highly non-polar compounds. Two occurred through free radical reactions with one derivative resulting from a broken $\mathrm{C}-\mathrm{C}$ bond and the other resulting from the removal of a nitro group. The latter became 1,2,3,5,6,7,8 heptanitrocubane. Another derivative occurred through 
hydroxylation-nucleophilic reactions $\left(\mathrm{ONC}-\mathrm{NO}_{2}+\mathrm{OH}^{-}\right)$. The fourth derivative resulted from multiple reactions in which one $\mathrm{NO}_{2}$ and one $\mathrm{C}-\mathrm{C}$ were removed. Depending on the attacking group, results indicate Fenton or photo-induced free radical reactions to be the most likely transformation methods of choice.

\subsection{TNTAC (2,4,6,8-tetranitro 1,3,5,7-tetraaza-cubane)}

TNTAC and three of its derivatives were studied via MOPAC AM1 and MNDO. TNTAC, a cubane with four nitro groups emanating from the four cage carbon atoms, is comprised of alternating carbon and nitrogen atoms with nitro groups bonded only to the carbon atoms, Figure 1. Similar to ONC, the TNTAC nitro groups are attached to the carbon atoms of the cage (no N-N bonds), whereas HMX, RDX and CL-20 nitro groups are attached to the nitrogen atoms in the ring or cage. Each TNTAC carbon is bonded to four nitrogen atoms, three from the ring and one from the nitro group. All bonds are $\mathrm{C}-\mathrm{N}$ bonds, with the cage $\mathrm{C}-\mathrm{N}$ bonds being slightly longer and less polar within the molecule than those attached to the nitro groups [55-56]. According to our predictions, ONC and TNTAC exhibited the lowest HOMO/LUMO energies [55-56], but the highest formation energies, Figure 1. The latter makes TNTAC the hardest of the studied compounds to form. Although both ONC and TNTAC are non-polar, because their high degree of molecular symmetry cancels the effective polarity of their C-N bonds, TNTAC is the most non-polar. Due to: i) a high degree of symmetry; ii) even distribution of the charge among the $\mathrm{C}-\mathrm{N}$ bonds; and iii) the molecules being highly strained, the free radical mechanism is likely to predominate in symmetrically breaking these $\mathrm{C}-\mathrm{N}$ bonds.

\section{Conclusions and Summary}

Our hypothesis, proven computationally and spectroscopically, that molecular structure, under homologous conditions, determines preferred, theoretically predictable degradation pathways enables prediction of potential environmental impact of NOCs from their molecular structure. This hypothesis applies to the large number and structural variety of NOCs and their multivariate transformations as well as to both large and small molecules. Following the course and assessing degradation pathways of NOCs enables further predictions in terms of environmental risk - shortening research and application time and, thereby, expense through elimination of the chemically unfeasible.

While use of computational predictive methods saves time, labor and cost by revealing possibilities which can be verified experimentally and further explored at different levels of computation, combining computational chemistry with experimental, particularly spectroscopic, techniques is appropriate not only to verify concept and predictive results, but also to determine what is chemically feasible, thus, providing a viable, powerful and relatively inexpensive tool which we highly recommend. This review of our computational and spectroscopic research described competitive degradation mechanisms of nitroaromatic and nitramine compounds by free radical oxidative, reductive and alkaline hydrolysis, relating them, when possible, to environmental risk. Problems in assessing the toxicity of NOCs and their intermediates in the environment are as great as the variety of possible reactive transitions. Also, transformation processes that may work in one mini-environment may not work in another due to either apparent or obscure differences difficult to control. 
Listed are selected observations in brief: i) Polymerization can cause creation of toxic compounds, and some di-azo polymers of TNT can be expected to be toxic - similar to certain azo dyes. However, RDX and HMX do not polymerize; ii) $\mathrm{OH}^{-}$groups render molecules they are attached to more water soluble, facilitating metabolism; iii) Applicable to TNT, under certain conditions, two adjacent $\mathrm{OH}^{-}$ can yield a water molecule and form an epoxy - a cause of carcinogenicity; iv) Ortho are generally more toxic than para substituted amines; v) Two adjacent hydroxyl groups or two hydroxyl groups para to each other may cause the aromatic parent compound to decompose into smaller molecules less toxic than the parent; vi) RDX and HMX are less apt to bind to media than TNT; therefore, their dispersal into the environment is expected to be greater; vii) Free radicals are reactive and as such can affect type and degree of toxicity. Thus, non-ionic environmental media containing free radical inducing compounds can be expected to affect environmental toxicity.

As data is compiled and published, a theoretical framework develops that is expected to provide environmental scientists with means to predict, evaluate and develop new protocols for emerging NOCs and their environmental interactions for the purpose of developing capabilities to manage them.

\section{Acknowledgements}

This work was supported by the Environmental Quality Technology Program managed by the U.S. Army Research and Development Center (ERDC), Vicksburg, MS and the Department of Defense Strategic Environmental Research and Development Program. We appreciate the encouragement of Dr. John Cullinane, ERDC Technical Director for Environmental Engineering; Dr. Richard Price, Division Chief and Branch Chief, Dr Rick Lance. We thank Drs. Karl Indest, Sandra Brasfield, Mark Chappell and Ed Perkins for their helpful suggestions.

\section{References}

1. Brannon, J.; Deliman, P.; Gerald, J.; Ruiz, C.; Price, C.; Hayes, C.; Yost, S.; Qasim, M. Conceptual Model and Processes Descriptor Formulations for Fate and Transport of UXO. Tech IRRP-99-1, USACE, WES: Vicksburg, 1999.

2. Chilkapati, A.; Ginn, A.; Szecsody, J. An Analysis of Complex Reaction Networks in Groundwater Modeling. Water Resources Res. 1988, 34(7), 1767-1780.

3. Hawari, J. ; Deschamps, S. ; Beaulieu, C. ; Paquet, L.; Halasz, A. Photodegradation of CL-20: insights into the mechanisms of initial reactions and environmental fate. Elsevier Water Research 2004, 38, 4055-4064.

4. Stahl, J.; Aust, S. Biodegradation of 2,4,6-Trinitrotoluene by the White Rot Fungus Phanerochaete Chrysosporium. In Biodegradation of Nitroaromatic Compounds; Spain, J., Ed.; Plenum Press: New York, 1994; Environmental Science Research, Vol. 49, pp. 117-133.

5. Szecsody, J.; Girvin, D.; Devary, B.; Campbell, J.; Fredrickson, H.; Crocker, F.; Qasim, M.; Riley, R.; Gamerdinger, A.; Lemond, L.. Factors Effecting the Fate and Transport of CL-20 in the Vadose Zone and Groundwater: Progress Report for 2003. End of Year Tech. Report, 12/2003.

6. Szecsody, J. et al. Sorption \& oxic degradation of the explosive CL-20 during transport in subsurface sediments. Chemosphere 2004, 56, 593-610. 
7. Ainsworth, C.; Harvey, S.; Szecsody, J. Relationships between the leachability characteristics of unique energetic compounds and soil properties, Rep. 91PP1800.; US Army Med. Res., 1993.

8. Ownby, D.; Belden, J.; Lotufo, G.; Lydy, M. Accumulation of trinitrotoluene (TNT) in aquatic organisms: Part I - Bioconcentration and distribution in channel catfish (Ictalurus punctatus). Chemosphere 2005, 58, 1153-1159.

9. Ownby, D.; Belden, J.; Lotufo, G.; Lydy, M. Accumulation of trinitrotoluene (TNT) in aquatic organisms: Part II - Bioconcentration in aquatic invertebrates and potential for trophic transfer to channel catfish (Ictalurus punctatus). Chemosphere 2005, 58, 1161-1168.

10. Weissmahr, K.; Haderlein, S.; Schwarzenbach, R. In Situ Spectroscopic Investigations of Adsorption Mechanisms of Nitroaromatic Compounds at Clay Minerals. Environ. Sci. Technol. 1997, 31,240-247.

11. Dodard, S.; Renoux, A.; Hawari, J.; Ampleman, G.; Thiboutot, S.; Sunahara, G. Ecotoxicity Characterization of Dinitrotoluenes and some of their reduced metabolites. Chemosphere 1999, 38, 2071-2079.

12. Etnier, E. Water quality criteria for hexahydro-1,3,5-trinitro-1,3,5-triazine (RDX). Regul Toxico. Pharm. 1989, 9, 147-57.

13. Honeycutt, M.; Jarvis, A.; McFairland, V. Cytotoxicity and Mutagenicity of 2,4,6-Trinitrotoluene and Its Metabolites. Exotoxicology and Environmental Safety 1996, 35, 282-287.

14. Lachance, B.; Robidoux, P.; Hawari, J.; Ampleman, G.; Thiboutot, S.; Sunahara, G. Cytotoxic and genotoxic effects of energetic Compounds on bacterial and mammalian cells in vitro. Genetic Toxicol. and Environ Mutagenesis, Mutation Res. 1999, 444, 25-39.

15. Robidoux, P.; Hawari, J.; Thiboutot, S. Acute and chronic toxicity of the new explosive CL-20 to the earthworm (eisenia Andrei) exposed to amended natural soils. Environ. Toxico. Chem. 1999, $23,1026$.

16. Sciences International, Inc. Toxicological Profile for 2,4,6-Trinitrotoluene; U.S. Department of Health and Human Services, June 1995.

17. Bajpai, R.; Kim, J.; Qasim, M. Bioremediaion. In Ency. of Agriculture, Food, and Biological Engineering. CRC Press: Boca Raton, 2003, 108-118.

18. Adam, M.; Comfort, S.; Morley, M.; Snow, D. Remediating RDX-Contaminated Ground Water with Permanganate: Laboratory Investigation for the Pantex Perched Aquifer. J. of Environmental Quality 2004, 33, 2165-2173.

19. Balakrishnan, V.; Halasz, A.; Hawari, J. Alkaline Hydrolysis of the Cyclic Nitramine Explosives, RDX, HMX and CL-20: New Insights into Degradation Pathways Obtained by the Observation of Novel Intermediates. Environ. Sci. Tech. 2003, 37, 1838-1843.

20. Balakrishnan, V.; Monteil-Rivera, F.; Halasz, A.; Corbeanu, A.; Hawari, J. Decomposition of the Polycyclic Nitramine Explosive, CL-20 by Fe(0). Environ. Sci. Technol. 2004, 38, 6861-6866.

21. Bernasconi, C. Kinetic and Spectral Study of Some Reactions of 2,4,6-Trinitrotoluene in Basic Solution. I. Deprotonation and Janovsky Complex Formation. J. Org. Chem. 1971, 36, 1671-679.

22. Brannon, J.; Qasim, M.; Price, C.; Yost, S. Photodegradation of TNT in Water \& Sediment/Water Systems. WES Rep., Env. Eng. Div.-USAE, WES, 1998.

23. Bonin, P.; Bejan, D.; Schutt, L.; Hawari, J.; Bunce, N. Electrochemical Reduction of Hexahydro1,3,5-trinitro-1,3,5-triazine in Aqueous Solutions. Environ. Sci. Technol. 2004, 38 (5), 1595-99. 
24. Emmrich, M. Kinetics of the Alkaline Hydrolysis of Important Co-contaminants of 2,4,6Trinitrotoluene in Highly Contaminated Soils. Environ. Sci. Technol. 2001, 35, 874-877.

25. Emmrich, M. Kinetics of the Alkaline Hydrolysis of 2,4,6-Trinitrotoluene in Aqueous Solution and Highly Contaminated Soils. Environ. Sci. Technol. 1999, 33, 3802-3805.

26. Hansen, L.; Larson, S.; Fell, D.; Qasim, M.; Cullinane, M. Based-Catalyzed Transformations of Explosive Compounds in Soil \& Water. In Proceedings of the USACE Env. Dev. Workshop, Portland, OR, 2001.

27. Heilmann, H.; Wiesmann, U.; Stenstrom, M. Kinetics of Alkaline Hydrolysis of High Explosives RDX and HMX in Aqueous and Adsorbed to Activated Carbon. Environ. Sci. Technol. 1996, 30, 1485-1485.

28. Heilmann, H.; Stenstrom, M. Hesselmann, R.; Wiesmann, U. Kinetics of the aqueous alkaline homogeneous hydrolysis of high explosive 1,3,5,7-tetraaza 1,3,5,7-tetranitrocyclooctane (HMX). Water Sci. Technol. 1994, 30, 53-61.

29. Li, Z.; Shea, P.; Comfort, S. Destruction of 2,4,6-Trinitrotoluene by Fenton Oxidation. J. Env. Quality. 1997, 26, 480-487.

30. Agrawal, A.; Tratnyek, P. Reduction of nitroaromatic compounds by zero-valent iron metal. Environ. Sci. Technol. 1966, 30, 153-160.

31. Bier, E.; Singh, Z.; Li, S.; Comfort, S.; Shea, P. Remediating hexahydro-1,3,5-trinitro-1,3,5triazine-contaminated water and soil by Fenton oxidation. Env. Toxicol. Chem. 1999, 18, 10781084.

32. Christensen, H. et al. Reactions of Hydroxyl Radicals with Hydrogen Peroxide at Ambient and Elevated Temperatures. J. Phys. Chem. 1982, 86 (9), 1588-1590

33. Hundal, L.; Singh, J.; Bier, E.; Shea, P.; Comfort, S.; Powers, W. Removal of TNT and RDX from water and soil using iron metal. Environ. Pollut. 1997, 97, 55-64.

34. Singh, J.; Comfort, S.; Shea, P. Remediating RDX-contaminated water and soil using zero-valent iron. J. Environ Qual. 1998, 27, 1240-1245.

35. Melius, C. Thermochemical modeling. I. Application to decomposition of energetic materials. Chemistry and Physics of Energetic Materials. Bulusu, S. N. Ed. Kluwer: Dordrecht, Netherlands, 1990, 21-49.

36. Schmelling, D.; Gray, K.; Kamat, P. Role of Reduction in the Photocatalytic Degradation of TNT. Environ. Sci. Technol. 1996, 30, 2547-2555.

37. Thorn, K.; Thorne, P.; Cox, L. Alkaline Hydrolysis/Polymerization of 2,4,6-Trinitrotoluene: Characterization of Products by 13C and 15N NMR. Environ. Sci. Technol.2004, 38, 2224-2231.

38. Wight, C.; Botcher, T. Thermal decomposition of solid RDX begins with N-N bond scission. $J$. Am. Chem. Soc. 1992, 114, 8030-8304.

39. Zappi, M.; Miller, J.; Qasim, M. Development of Chemical Oxidation Processes for Use in Remediating Conaminated Department of Defense Sites. In Special Publ. on Military Res. Act.; Am. Soc. of Agronomy, 1996.

40. Zhao, X.; Hintsa, E.; Lee, Y. Infrared multiphoton dissociation of RDX in a molecular beam. $J$. Chem. Phys. 1988, 88, 801-810. 
41. Bajpai, R.; Qasim, M.; Hansen, L.; Popovic, M.; Paco, J. Chemical and Biological Reactions of TNT \& RDX. In Proceedings of the International Congress of Chemistry \& Process Engineering, Chisa, Czech Republic, Aug 25-29, 2002; pp. 15.

42. Bajpai, R.; Parekh, D.; Herrmann, S.; Popovic, M.; Paca, J.; Qasim, M. A kinetic model of aqueous-phase alkali hydrolysis of 2,4,6-trinitrotoluene. J. Haz. Mat. 2004, 106B, 55-66.

43. Karasch, C.; Popovic, M.; Qasim, M.; Bajpai, R. Alkali Hydrolysis of Trinitrotoluene. Biochem. \& Biotech. 2002, 14, 1176-1186.

44. Michalkova, A.; Rasulev, B.; Qasim, M.; Gorb, L.; Furey, J.; Fredrickson, H.; Leszczynski, J. Explosives: Modeling their interactions with Clay Minerals and Toxicity. AHPCRC Bulletin, 55458-1459; Army High Performance Computer Research Center: Minneapolis, MN, 2006.

45. Bhushan, B.; Halasz, A.; Spain, J.; Hawari, J. Initial Reaction(s) to Biotransformation of CL-20 is Catalyzed by Salicylate 1-Monooxygenase from Pseudomonas sp. Strain ATCC 29352. Appl. \& Environ. Microbiology. 2004, 7, 4040-4047.

46. Coleman, N.; Nelson, D.; Duxbury, T. Aerobic biodegradation of the hexahydro-1,3,5-trinitro1,3,5-triazine (RDX) as a nitrogen source by a Rhodococcus sp., strain DN22. Soil Biol. Biochem. 1998, 30, 1159-1166.

47. Fournier, D.; Halasz, A.; Spain, J.; Spanggord, R.; Bottaro, J.; Hawari, J. Biodegradation of the Hexadydro-1,3,5-Trinitro-1,3,5-Triazine Ring Cleavage Producing 4-Nitro-2,4-Diazabutanol by Phanerochaete chrysosporium. Appl. \& Environ. Microbiology, 2004, 70(2), 1123-1128.

48. Hawari, J. Biodegradation of RDX and HMX: from Basic Research to Field Application; In Biodegradation of Nitroaromatic Compounds and Explosives; Spain, J, Hughes, J., Knackmuss, H., Eds.; Lewis Pub: Boca Raton, FL, 2000; pp. 278-310.

49. Krumholz, L.; Li, J.; Clarkson, W.; Wilber, G.; Suflita, J. Transformations of TNT and related aminotoluenes in groundwater aquifer slurries under different electron-accepting conditions. $J$. Indus. Microbiology \& Biotech. 1997, 18(2-3), 161-169.

50. Qasim, M.; Bajpai, R.; Hansen, L. Nucleophilic Reactions of TNT with $\mathrm{OH}^{-}$for Enhancement of Biodegradation; Oral Presentation, 4th Int. Conf. TiO2 Photocat. Purification \& Treat. of Water \& Air, part of: $5^{\text {th }}$ Int. Conf. on Adv. Oxida.Tech. for Water \& Air Remediation, Albuquerque, NM, May, 1999.

51. Spain, J. In Biodegradation of Nitroaromatic Compounds and Explosives. Spain, J., Hughes, J., Knackmuss, H.-J., Eds.; CRC Press: Boca Raton, FL, 2000; Chapter 1.

52. Binks, P.; Nicklin, S.; Bruce, N. Degradation of hexahydro-1,3,5-trinitro-1,3,5-triazine (RDX) by Stenotrophomonas maltophilia PBI. Appl. Environ. Microbiol. 1995, 61, 1318-1322.

53. Wackett, L. Evolution of enzymes for the metabolism of new chemical inputs in the environment. J. Biol. Chem. 2004, 279, 41259 - 41262.

54. Politzer, P.; Murray, J.; Seminario, J.; Lane, P.; Grice, M.; Concha, M. Computational characterization of energetic materials. J. Molecular Structure (Theochem.). 2001, 573, 1-10.

55. Qasim, M.; Fredrickson, H.; McGrath, C.; Bajpai, R. Modes of Degradation of Cyclic Nitramines: An Approximation Methods Comparison of the Relationships Between the Structures and Reactivities of CL-20, ONC, TNTAC, and RDX; Oral presentation; 11th Conference on Current Trends in Computational Chemistry, Jackson, MS, 2002. 
56. Qasim, M.; Fredrickson, H.; Furey, J.; McGrath, C. Theoretical Predictions of Chemical Degradation Reaction Mechanisms of Cyclic (RDX, HMX) and Cage Cyclic (CL-20, ONC, TNTAC) Nitramines as Related to Their Molecular Structures with Experimental Verification Using CL-20 as Model; SERDP/ESTCP: Washington, DC, 2003.

57. Qasim, M.; Furey, J.; Fredrickson, H.; Szecsody, J.; McGrath, C.; Bajpai, R. Semiempirical Predictions of Chemical Degradation Reaction Mechanisms of CL-20 as Related to Molecular Structure. J. Structural Chemistry. 2004, 15 (5), 493-499.

58. Qasim, M.; Fredrickson, H.; Honea, P.; Leszczynski, J.; Okovytyy, S.; Szecsody, J.; Kholod, Y. Prediction of CL-20 Chemical Degradation Pathways, Theoretical and Experimental Evidence for Dependence on Competing Modes of Reaction. SAR and QSAR in Env. Res. 2005, 16 (5), $495-$ 515.

59. Qasim, M.; Fredrickson, H.; McGrath, C.; Furey, J.; Bajpai, R. Theoretical Predictions of Chemical Degradation Reaction Mechanisms of RDX and Other Cyclic Nitramines Derived from Their Molecular Structures. SAR/QSAR in Environ. Res. 2005, 16 (3), 203-218.

60. Qasim, M.; Honea, P.; Gorb, L.; Leszczynski, J. Molecular Structure Determines Chemical Reactivities and, Thus, Transformation Pathways. In Proceedings of the 25th Army Science Conference, Orlando, FL, 2006.

61. Isayev, O.; Rasulev, B.; Gorb, L.; Leszczynski, L. Structure-Toxicity Relationships of Nitroaromatic Compounds. J. Mol. Diver. 2006, 10 (2), 233-245.

62. Stewart, J. MOPAC 2000 Manual; Fujitsu Limited, 1999.

63. Okovytyy, S.; Kholod, Y.; Qasim, M.; Frederickson, H.; Leszczynski, J. The Mechanism of Unimolecular Decomposition of CL-20 (2,4,6,8,10,12 Hexanitro-2,4,6,8,10,12-Hexaazaisowurtzitane). A Computational DFT Study. Technical Report for Army High Performance Computing Research Center, Report Number 2004-177.

64. Kholod, Y.; Okovytyy, S.; Qasim, M.; Honea, P.; Furey, J.; Fredrickson, H.; Leszczynski, J. A DFT Study of the IR and UV/VIS Spectra of CL-20 Degradation Products. In Proceedings of the 5th Southern Schl. on Computaional Chemistry, Jackson, MS, Apr 8-9, 2005.

65. Okovytyy, S.; Kholod, Y.; Qasim, M.; Frederickson, H.; Leszczynski, J. The Mechanism of Unimolecular Decomposition of CL-20 (2,4,6,8,10,12 Hexanitro-2,4,6,8,10,12Hexaazaisowurtzitane). A Computational DFT Study. J. Phys. Chem. 2005, 109, 2964-2970.

66. Kuz'min, V.; Muratov, E.; Artemenko, A.; Gorb, L.; Qasim, M.; Leszczynski, J. QSAR analysis and virtual screening of nitroaromatic toxicity in vivo. J. Mol. Mod. 2005, 11, 457-467 (and references cited therein).

67. Rieger, P.; Knckmuss, H. Basic knowledge and perspectives on biodegradation of 2,4,6trinitrotoluene and related nitroaromatic compounds in contaminated soil. Biodegradation of Nitroaromatic Compounds. Spain, J. C. , Ed. Plenum Press: New York. 1995, 1-18.

68. Haderlein, S.; Hofstetter, T.; Schwarzenbach, R. Surface Chemistry of Nitroaromatic Compounds. In Biodegradation of Nitroaromatic Compounds and Explosives; Spain, J.C., Hughes, J.B., Knackmuss, H.J, Eds.; CRC Press: Boca Raton, FL, 2000.

69. Davis, E.; Boopathy, R.; Manning, J. Use of trinitrobenzene as a nitrogen source by Pseudomonas vesicularis isolated from soil. Curr. Microbiology. 1997, 34 (3), 192-197. 
70. Boopathy, R.; Manning, J. Surfactant-Enhanced Bioremediation of Soil Contaminated with 2,4,6Trinitrotoluene in Soil Slurry Reactors. Water Environment Research. 2001, 71, 19-24.

71. Meharg, A.; Dennis, G.; Calmey, J. Biotransformation of 2,4,6-trinitrotoluene (TNT) by ecomycorrhizal basidiomycetes. Chemosphere 1997, 35 (3), 513-521.

72. Hawari, J.; Halasz, A.; Sheremata, T.; Beaudet, S.; Groom, C.; Paquet, L.; Rhofir, L.; Ampleman, G.; Thiboutot, S. Characterization of metabolites during biodegradation of hexahydro-1,3,5trinitro-1,3,5 triazine (RDX) with municipal anaerobic sludge. Appl. Environ. Microbiol. 2000, $66,2652-2657$.

73. McCormick, N.; Cornell, J.; Kaplan, A. Biodegradation of hexahydro-1,3,5-trinitro-1,3,5 triazine. Appl. Environ. Microbiol. 1981, 42, 817-823.

74. McCormick, N.; Cornell, J.; Kaplan, A. The anerobic biotransformation of RDX, HMX and their acetylated derivatives. Technical Report for the US Army Natick Res. \& Dev. Center, Natick, MA, AD Rep. A149464 (TR85-008), 1985.

75. Rajan, J.; Valli, K.; Perkins, R.E.; Sariaslani, F.; Barns, S.; Reysenbach, A.; Rehm, S.; Ehringer, M.; Pace, N. Mineralization of 2,4,6-Trinitrophenol (Picric acid); Characterization and Phylogenic Identification of Microbial Strains. J. Indus. Microbiol. 1996, 16, 319-324.

76. Vorbeck, C.; Lenke, H.; Fischer, P.; Knackmuss, H. Identification of a Hydride-Meisenheimer Complex as a Metabolite of 2,4,6-Trinitrotoluene by a Mycobacterium Strain. J. Bacteriology 1994, 176 (3), 932-934.

77. Major, M. Conversion of TNT to Biodegradable Compounds by Dissolution in Alkaline Solutions. Submitted, U.S. Army Center for Health Promotion and Preventive Medicine, Aberdeen Proving Ground, MD. Army Technical Manual TM9-1300-214, Ref.1, 1998.

78. Carper, W.; Davis, E.; Extine, M. Molecular Structure of 2,4,6-Trinitrotoluene. J. Phys. Chem. 1982, 86, 459-459.

79. Carey, F. Organic Chemistry; McGraw-Hill: New York, 1994; pp. 418-424, 448-461.

80. Ege, S. Organic Chemistry; Heath and Co.: Lexington, MA, 1989, pp. 555+, 967.

81. Fessenden, R.; Fessenden, J. Organic Chemistry; Willard Grant Press: Boston, MA, 1982.

82. March, M. Advanced Organic Chemistry: Reactions, Mechanisms and Structure, 4th Ed; Wiley: 1982; pp. 652. (A $5^{\text {th }}$ edition of the March book was edited by M. Smith, 2001)

83. McMurray, J. Organic Chemistry; Brooks/Cole Pub.: Pacific Grove, CA, 1988; pp. 548-565.

84. Morrison, R.; Boyd, R. Organic Chemistry, 5th Ed.; Allyn and Bacon: Boston, MA, 1987.

85. Streitwieser, A.; Heathcock, C.; Kosower, E. Introduction to Organic Chemistry; Macmillan: New York, 1987; pp. 780-781.

86. Qasim, M.; Honea, P.; Gorb, L.; Leszczynski, J. Molecular Structure Determines Chemical Reactivities and, Thus, Transformation Pathways; both published (best paper in category) and oral presentation, $25^{\text {th }}$ Army Science Conference, Orlando, FL, Nov, 2006.

87. Qasim, M.; Hansen, L.; Bajpai, R. Minimized Energy Calculations of TNT and Its Possible Transformation Products under Competing Conditions. Oral presentation, 7th Conference on Current Trends in Computaional Chemistry, Vicksburg, MS, Nov, 1998.

88. Qasim, M.; Honea, P.; Fredrickson, H. Comparative Study of Reaction Mechanisms of TNT and Selected Analogues Using Free Radical Generators and Alkaline Hydrolysis. Oral presentation, 2nd DoD Sustainable Ranges Initiative, San Antonio, TX, Aug 22-25, 2005. 
89. Chakraborty, D.; Muller, R.; Dasgupta, S.; Goddard, W., III. The Mechanism for Unimolecular Decomposition of RDX (1,3,5-Trinitro-1,3,5-triazine), an ab initio study. J. Phys. Chem A. 2000, 104, 2261-2272.

90. Qasim, M.; Hansen, L. Two Pathways generated through approximation methods: a mechanistic study of RDX Degradation. Oral presentation, 9th Conference on Current Trends in Computational Chemistry, Vicksburg, MS, Nov 4, 2000.

91. Sewell, T.; Thompson, D. Classical dynamics study of unimolecular dissociation of hexahydro1,3,5-trinitro-1,3,5-triazine. J. Phys. Chem. 1991, 95, 6228-6242.

92. Rice, B.; Sorescu, D. Assessing a Generalized CHNO Intermolecular Potential through ab Initio Crystal Structure Prediction. J. Phys. Chem. B 2004, 108, 17730-17739.

93. Monteil-Rivera, F.; Paquet, L.; Deschamps, S.; Balakrishnan, V.; Beaulieu, C.; Hawari, J. Physico-chemical measurements of CL-20 for environmental applications comparison with RDX and HMX. Elsevier, J. of Chromatog. A 2004, 1025, 125-132.

94. Lewis, J.; Glaesemann, K.; VanOpdorp, K.; Voth, G. Ab Initio Calculations of Reactive Pathways for $\alpha$-Octahydro-1,3,5,7-tetranitro-1,3,5,7-tetrazocine ( $\alpha$-HMX). J. Phys. Chem. A 2000, 104, 11384-11386.

95. Lewis, J.; Sewell, T.; Evans, R.; Voth, G. Electronic Structure Calculation of the Structures and Energetics of the Three Pure Polymorphic Forms of Crystalline HMX. J. Phys. Chem. B 2000, 104, 1009-1013.

96. Sorescu, D.; Rice, B.; Thompson, D. Molecular Packing \& NPT-Molecular Dynamics Investigation of the Transferability of the RDX Intermolecular Potential to 2,4,6,8,10,12Hexanitrohexaazaisowurtzitane. J. Phys. Chem. B 1998, 102, 948-52.

97. Nielsen, A.; Chafin, S.; Christian, D.; Moore, M.; Nadler, R.; Nissan, D. Synthesis of polyazapolycylic caged Polynitramines. Tetrahedron 1998, 54, 11793-11812.

98. Nielsen, A. Nitrocarbons. In Organic Nitro Chemistry Series; VCH Publishers: New York, 1995.

99. Chan, M.; Boggs, T. Advanced CL-20 Based propellant Formulated by China Lake Team, 02/07/2001.

100. Research Team, Naval Weapons Center, China Lake, CA. Technical reports regarding CL-20, separate booklets: Parts 1-8, 1990-1994.

101.Honea, P.; Qasim, M.; Fredrickson, H.; Furey, J.; Okovytyy, S.; Kholod, Y.; Leszcynski, J. Stopped-Flow and UV-VIS Spectrophotometric Studies of the Transformation of CL-20. Poster presented at the 13th Conference on Current Trends in Computational Chemistry, Nov 12-13, 2004.

102. Qasim, M.; Simplified Concepts in Spectroscopy and Photochemistry, USAE WES Tech. Rep. IRRP-97- 4/1997.

103. Clark, G.; Hawley, G. The Encyclopedia of Chemistry, 2nd Ed.; Reinhold Publ. Corp.: New York, 1966.

104. Dean, J. Lange's Handbook of Chemistry, 14th Ed.; McGraw-Hill: New York, 1992.

105. Lide, D., Ed. Handbook of Chemistry and Physics, 76th Ed.; CRC Press: Boca Raton, FL, 1996.

106. Nielson, A. Nitrocarbons Organic Nitro Chemistry Series. VCH Publishers: New Jersey, 1995.

107.Bard, A., Dekker, M., Eds.; Encyclopedia of Electrochemistry of the Elements; Marcel Dekker Inc, New York, 1976; Volume 8. 
108. Patai, S. The Chemistry of the Carbon Nitrogen Double Bond; Interscience Pub.: London, UK, 1970.

109.Kholod, Y.; Okovytyy, S.; Kuramshina, G.; Qasim, M.; Gorb, L.; Leszczynski, J. An Analysis of stable forms of CL-20: A DFT study of conformational transitions, infrared and Raman spectra. $J$. Mol. Struct. 2007, 843, 14-25.

C 2007 by MDPI (http://www.mdpi.org). Reproduction is permitted for noncommercial purposes. 